\title{
Estudio del otoño lluvioso de 1991 en Navarra
}

\author{
Javier María Pejenaute Goñ *
}

En los últimos años, el otoño, que tradicionalmente era bastante húmedo en la Comunidad Navarra, ha resultado muy seco. El mes de septiembre ha sido un período prolongación del verano con temperaturas cálidas y escasas precipitaciones registradas. Esta sequía se ha prolongado también a los meses de octubre e incluso noviembre, períodos que tradicionalmente eran lluviosos en Navarra, según las series de datos históricos.

Entre los últimos otoños hay que recordar, sobre todo, el de 1988 (Pejenaute Goñi, «Estudio del período seco otoño-invierno 1988-89 en Navarra", Notas y Estudios de Ciencias Sociales 3) en que las precipitaciones estuvieron muy poco presentes, y el de 1989 (PEJENAUTE GOÑI, «El comportamiento climático original de los meses de noviembre y diciembre de 1989 en Navarra", Notas y Estudios de Ciencias Sociales 4), también con precipitaciones anormalmente bajas, debido, entre otras cosas, al predominio de las situaciones atmosféricas de procedencia meridional, que son muy secas en Navarra.

El otoño de 1991 ha merecido nuestra atención por ser una vuelta a lo que ocurría antaño durante esta estación, es decir a las precipitaciones originadas por la bajada del frente polar después del período estival. En efecto, después de un verano seco y una ola de calor a finales de agosto, se han dado tres meses otoñales muy lluviosos en Navarra, con un septiembre que ha registrado altas precipitaciones, situándose entre los de más altos registros del siglo, en cuanto a cantidad de lluvia caída.

Se trata, asi pues, de una buena oportunidad para estudiar un otoño lluvioso en Navarra, para observar las situaciones atmosféricas que lo

\footnotetext{
* Prof. tutor de Geografía del Centro Asociado de Navarra.
} 
originan, y para ver el comportamiento pluviométrico de las diferentes comarcas navarras ante estas situaciones lluviosas. Además se interrumpe la cadena de otoños secos de los últimos años y se pueden comparar los otoños secos y lluviosos de cara a obtener unas conclusiones precisas que, en definitiva, nos ayuden a profundizar en el estudio del clima de nuestra Comunidad.

Este es pues el objetivo de este artículo: estudiar el otoño de 1991, caracterizado en principio por las abundantes precipitaciones tras unos años de sequía y resaltar las zonas más y menos irrigadas de nuestra territorio, en un intento de explicación de las causas que originan estos resultados.

Para su elaboración se han utilizado, en primer lugar, las tarjetas mensuales de precipitaciones correspondientes a diez observatorios representativos de todas las comarcas navarras, fiables, y en su mayor parte con series históricas de larga duración, que me han sido facilitadas atentamente en el Servicio de Estructuras Agrarias, Climatología y Suelos, del Gobierno de Navarra (Tabla 1).

\section{TABLA I. RED DE LOS OBSERVATORIOS UTILIZADOS}

\begin{tabular}{lcc}
\hline OBSERVATORIOS & ALTITUD $(\mathrm{m})$ & \multicolumn{2}{c}{ COORDENADAS } \\
\hline 1. Artikutza & 300 & $43^{\circ} 13^{\prime} \mathrm{N} .1^{\circ} 54^{\prime} \mathrm{E}$. \\
2. Santesteban & 131 & $43^{\circ} 08^{\prime} \mathrm{N} .2^{\circ} 02^{\prime} \mathrm{E}$. \\
3. Eugui-Esteribar & 615 & $42^{\circ} 58^{\prime} \mathrm{N} .2^{\circ} 10^{\prime} \mathrm{E}$. \\
4. Abaurrea Alta & 1.047 & $42^{\circ} 54^{\prime} \mathrm{N} .2^{\circ} 29^{\prime} \mathrm{E}$. \\
5. Alsasua & 520 & $42^{\circ} 54^{\prime} \mathrm{N} .1^{\circ} 31^{\prime} \mathrm{E}$. \\
6. Pamplona-Observ. & 449 & $42^{\circ} 49^{\prime} \mathrm{N} .2^{\circ} 03^{\prime} \mathrm{E}$. \\
7. Alloz & 475 & $42^{\circ} 42^{\prime} \mathrm{N} .1^{\circ} 45^{\prime} \mathrm{E}$. \\
8. Yesa & 489 & $42^{\circ} 37^{\prime} \mathrm{N} .2^{\circ} 30^{\prime} \mathrm{E}$. \\
9. Carcastillo & 340 & $42^{\circ} 22^{\prime} \mathrm{N} .2^{\circ} 13^{\prime} \mathrm{E}$. \\
10. Fitero & 421 & $42^{\circ} 03^{\prime} \mathrm{N} .1^{\circ} 50^{\prime} \mathrm{E}$. \\
\hline
\end{tabular}

Además de estos diez observatorios básicos se han estudiado los datos mensuales de precipitaciones (precipitación total del mes, días de lluvia y precipitación máxima en un día) de cincuenta y seis observatorios de apoyo repartidos por todas las comarcas navarras, para lo cual se han utilizado los datos aportados por la revista Coyuntura agraria, que edita mensualmente la Secretaría Técnica del Departamento de Agricultura, Ganadería y Montes del Gobierno de Navarra.

Asimismo se han estudiado las series históricas de precipitaciones de algunos observatorios navarros, años 1941 a 1991, material facilitado en el Servicio de Estructuras Agrarias del Gobierno de Navarra, y que ha 
servido para observar las precipitaciones de otoño en los últimos cincuenta años.

Finalmente, se han analizado los mapas del Boletín Meteorológico Diario del Instituto Nacional de Meteorología, se ha hecho una clasificación diaria durante los tres meses de otoño teniendo en cuenta los mapas de superficie, y topografías de quinientos milibares y trescientos milibares principalmente.

\section{UN SEPTIEMBRE DE LOS MÁS LLUVIOSOS DEL SIGLO}

La actividad de la circulación de la atmósfera en el mes de septiembre de 1991, con la materialización de situaciones atmosféricas inestables y muy propicias para las lluvias, hizo de este mes uno de los más lluviosos que se conocen, según los datos aportados por las series históricas. Rompió así una racha de septiembres secos, prolongación del estío, que se venían sucediendo en Navarra.

Al observar los mapas del tiempo correspondientes a septiembre de 1991, se pueden establecer tres períodos diferentes. El primero de ellos, que abarca los doce primeros días, se caracterizó por la presencia de embolsamientos fríos encadenados, que se situaron al Oeste de Galicia y dieron lugar a chubascos tormentosos repartidos por toda la Comunidad Navarra. Prácticamente en todas las comarcas navarras se superaron los treinta milímetros de precipitación en dos días.

Se trata de una situación muy lluviosa en nuestra Comunidad. La borrasca fría, bien dibujada en las topografías altas y con una temperatura de dieciséis grados bajo cero en la topografía de quinientos milibares, dio lugar a que las masas de aire cálidas de superficie experimentasen fuertes ascensos, provocados por la presencia de aire frío de altura y diesen lugar a lluvias convectivas.

El esquema es muy simple e igual en todas las alturas: un anticiclón de orientación zonal que abarca el Centro de Europa se sitúa en las Islas Británicas, y un área de bajas presiones se ubica en Europa Meridional, con una lengua fría próxima a Galicia. Esta borrasca de niveles altos cambia su posición, y afecta, en mayor o menor medida, a nuestra área de estudio.

Entre los días trece y veintidós se desarrolla un segundo período, caracterizado por la escasa presencia de lluvias, interrumpido tan solo por la presencia de algunas precipitaciones tormentosas de poca intensidad, con cantidades, a veces inapreciables y desigualmente repartidas. 
TABLA II. FRECUENCIA PORCENTUAL DE LAS SITUACIONES ATMOSFÉRICAS (\%)

\begin{tabular}{lccccccccccr}
\hline & N. & NE. & E/SE S/SW & W & W/AN & NW & BJ & BT & PB & ANT \\
\hline Septiembre & 3,3 & 3,3 & - & - & 10 & - & 6,7 & 33,3 & 16,7 & 10 & 16,7 \\
Octubre & 19,3 & 9,7 & 9,7 & 12,9 & 19,4 & 9,7 & 6,4 & 6,4 & - & 3,2 & 3,2 \\
Noviembre & 10 & 6,7 & - & 16,7 & 20 & 3,3 & 16,7 & - & - & 3,3 & 23,3 \\
Otoño & 10,9 & 6,6 & 3,2 & 9,9 & 16,5 & 4,3 & 9,9 & 13,2 & 5,6 & 5,5 & 14,4 \\
\hline
\end{tabular}

N: Norte; NE: Nordeste; E/SE: Este/Sudeste; S /SW: Sur/Sudoeste; W: Oeste; W/ AN: Oeste-anticiclónico; NW: Noroeste; BJ: Baja; BT: Baja térmica; PB: Pantano barométrico; ANT: Anticiclón.

Un anticiclón, bien visible en todas las alturas, corona la Península y permanece fijo durante varios días, asegurando el calor y el ambiente seco. En algunas ocasiones, en superficie, aparecen bajas presiones relativas y situaciones de indefinición bárica o pantanos barométricos, que no son inestables, pues no pueden romper la capa de inversión de altura.

Finalmente, a partir del día veintitrés y hasta el final, se suceden las precipitaciones generalizadas en Navarra, originadas por el paso de potentes vaguadas que dan lugar a situaciones lluviosas del Norte, del Noroeste e incluso del Oeste, pero con el común denominador de inestables y lluviosas.

El frente polar ha iniciado el descenso hacia nuestras latitudes y en altura la corriente en chorro circula por las proximidades de Navarra. El día veintiocho, una borrasca se sitúa en las inmediaciones de Bretaña y afecta al Cantábrico Oriental y a Navarra, y los dos días siguientes se registran cuantiosas lluvias.

Por lo tanto, el mes de septiembre se caracterizó por tener tres períodos diferentes. El primero de ellos lluvioso, originado por la presencia de embolsamientos fríos en el Atlántico, junto a Galicia. El segundo, supuso un paréntesis seco con presencia de anticiclones sobre nuestra vertical. $Y$ el tercero, caracterizado por la llegada de vaguadas lluviosas del frente polar con la corriente en chorro próxima a nuestra geografía, que dio lugar a precipitaciones importantes.

La frecuencia porcentual de las situaciones atmosféricas durante el mes de septiembre da una pista sobre las características lluviosas de dicho mes. Primeramente se puede apreciar, siguiendo la Tabla II, que las situaciones convectivas o de tormenta arrojan resultados importantes, sobre todo las correspondientes a las bajas frías, que suponen más de un tercio del mes y que son las que dieron lugar a las lluvias de los 
primeros días de septiembre. Junto a éstas, las bajas térmicas y los pantanos barométricos obtienen resultados altos de frecuencia, si bien no produjeron muchas lluvias.

Las situaciones del Noroeste y Oeste, que suelen ser muy lluviosas en Navarra, aparecen ambas en este mes con una frecuencia superior al quince por ciento. Fueron las que dieron lugar a las lluvias de los últimos días de septiembre. Finalmente, la situación anticiclónica, responsable de los días sin lluvias de mediados de mes, superaron el quince por ciento.

Los valles Cantábricos fueron los que mayor cantidad de precipitación recogieron, por su situación junto al Cantábrico Oriental. Tanto la gota fría situada en las proximidades de Galicia como las vaguadas que circularon los últimos días, proporcionaron fuertes lluvias. El valle del Urumea-Añarbe y los observatorios situados en el extremo Norte fueron los más irrigados con cantidades por encima de los doscientos cincuenta milímetros (Artikutza $306 \mathrm{~mm}$, Bera 251,8 mm, Zugarramurdi $278 \mathrm{~mm}$ ). Sin duda, su situación junto a las pantallas condensadoras de los macizos de Cinco Villas y Quinto Real, propiciaron estas altas Iluvias.

El resto de los observatorios registra una cantidad inferior pero con numerosas variantes. Los valles de Leitzarán y Araitz, y la zona de LesakaEtxalar obtienen más de doscientos milímetros (Betelu $224 \mathrm{~mm}$, Etxalar $232,5 \mathrm{~mm}$, Leitza $223,3 \mathrm{~mm}$ ). Finalmente los lugares más resguardados, a la sombra de los citados macizos, no alcanzan los doscientos milímetros, y algunos, como la regata del Bidasoa, no superan los ciento cincuenta (Sunbilla 139,2 mm, Santesteban 143,9 mm). Los valores pluvométricos aumentan en las montañas (Azpírotz).

Los valles Pirenaicos fueron muy lluviosos en el mes de septiembre de 1991, pero en general llovió menos que en los valles Cantábricos. Las diferencias vienen dadas principalmente por la altitud y por la situación: los lugares más altos y las cabeceras de los valles son los más irrigados. Las situaciones de gota fría y los temporales de lluvia de final de mes, dieron lugar a cantidades elevadas de lluvia.

En muchos lugares de los Pirineos Centrales y Orientales se superaron los ciento cincuenta milímetros (Roncesvalles $171 \mathrm{~mm}$, Abaurrea Alta 163,7 $\mathrm{mm}$, Urzainqui $193 \mathrm{~mm}$, Eugi $158 \mathrm{~mm}$ ). En el valle de Belagua, debido a la altura, se superaron los doscientos milímetros, resultados parecidos a los de los valles Cantábricos (Belagua $220 \mathrm{~mm}$ ). En cambio, en los observatorios más meridionales las cantidades recogidas fueron inferiores (Epároz 79,3 mm, Irotz 95,5 mm, Erro $125 \mathrm{~mm}$ ).

El corredor del Arakil y los valles meridionales húmedos (Basaburúa, Anué, Juslapeña) resultaron más lluviosos que las cuencas de Pamplona 
y de LumbierAóiz. En los primeros se superaron los ciento cincuenta milímetos, siendo tan irrigados como algunos lugares de los valles Cantábricos y Pirenaicos (Alsasua 168,8 mm, Irurtzun $180 \mathrm{~mm}$, Olague 165,8 $\mathrm{mm}$, Iraitzoz 170,9 mm), mientras que las cuencas se situaron próximas a los cien milímetros (Pamplona-Observ. $94,1 \mathrm{~mm}$, Noain $78,5 \mathrm{~mm}$, Monreal $102 \mathrm{~mm}$, llundain 125,9 mm). Las cantidades recogidas aumentaron considerablemente en las montañas y en algunos casos se situaron junto a los observatorios más lluviosos (Goñi $237,2 \mathrm{~mm}$ ).

En la Navarra Media, al Sur de las sierras Exteriores, las precipitaciones disminuyeron, sin embargo los observatorios próximos a las citadas montañas, tanto en la parte occidental como oriental, resultaron lluviosos y superaron siempre los cien milímetros, destacando la zona de Sangüesa próxima a la sierra de Leyre que registró una fortísima tormenta en la que Cáseda recogió 143,7 mm en un día (Larraona 149,3 mm, Genevilla 106,5 mm, Olóriz 141,2 mm, Leyre $137 \mathrm{~mm}$, Yesa $138 \mathrm{~mm}$ ).

Por el contrario, los lugares más bajos obtuvieron inferiores precipitaciones (Alloz 60,4 mm, Los Arcos 68,6 mm, Viana 54,2 mm, Estella 59,9 $\mathrm{mm}$ ). Resultados parecidos a los de la Ribera y que, en casi todos los casos, superaron los cincuenta milímetros. Algunos observatorios de la Ribera fueron más lluviosos que los de la Navarra Media, debido a las fuertes tormentas que registraron (Carcastillo 112,1 mm, Cadreita 96,4 $\mathrm{mm})$.

Por lo tanto, un septiembre muy lluvioso en el que destacaron por la alta cantidad recogida de lluvia, sobre todo, los valles Cantábricos y Pirenaicos, el corredor del Arakil y los valles meridionales húmedos.

Al estudiar las series históricas de algunos observatorios navarros desde el año 1941 hasta 1991 se observa las características pluviométricas originales de este mes, que se encuentra entre los más lluviosos de los cincuenta últimos años.

En Navarra Húmeda, el observatorio de Artikutza con una cantidad de agua recogida de $306 \mathrm{~mm}$ sólo ha sido superado por tres septiembres: el de 1959 que recogió $328,8 \mathrm{~mm}$, el de 1965 con $333,9 \mathrm{~mm}$ y el de 1984 con $320 \mathrm{~mm}$ En la serie pluviométrica de Santesteban aparecen nueve septiembres más lluviosos que este (143,9 $\mathrm{mm}$ en 1991), siendo el último, al igual que en Artikutza, el de 1984; el más lluvioso fue el de 1965 con $245,5 \mathrm{~mm}$.

En los valles Pirenaicos, desde 1941 hasta la actualidad, muy pocos septiembres han alcanzado la cifra de 1991, lo cual da una idea de las altas precipitaciones registradas. En Abaurrea Alta $(163,7 \mathrm{~mm}$ en septiembre de 1991) ha habido tan sólo tres meses más lluviosos y el último en 
1976; el más lluvioso fue el de 1965 con $302,4 \mathrm{~mm}$. En Eugi-Esteribar (158 mm en 1991) son ocho los meses más lluviosos, siendo el último el de 1969 con 222,6 mm; el más lluvioso fue el de 1949 con $273 \mathrm{~mm}$.

En el corredor de la Barranca, Alsasua $(168,8 \mathrm{~mm}$ en 1991) ha registrado el mes de septiembre más lluvioso desde 1959 y tan sólo ha sido superado en dos ocasiones desde 1941; en el año 1949 se recogieron $239,5 \mathrm{~mm}$. En la cuenca de Pamplona (Pamplona-Observatorio $94,1 \mathrm{~mm}$ en 1991) nueve septiembres han sido más lluviosos desde 1991 y el último en el año 1972; el más lluvioso fue el de 1969 con 197,9 mm de cantidad recogida.

En la Navarra Media el comportamiento ha sido diferente según las zonas. En la parte Occidental (Alloz 60,4 $\mathrm{mm}$ en 1991) ha registrado en trece ocasiones más cantidad y la última en el año 1975; en 1961 se recogieron $188,1 \mathrm{~mm}$. Por el contrario, en la parte oriental (Yesa $138 \mathrm{~mm}$ en 1991) sólo ha sido superado por dos años y desde 1959 no se registraba tal cantidad de lluvia; el año más lluvioso fue 1949 con 163,2 mm.

Finalmente en la Ribera los resultados fueron diferentes según la situación de los distintos observatorios. En Carcastillo (112,1 mm en 1991), sólo cuatro años han recogido mayor cantidad de lluvia y el último en 1962; el más lluvioso fue el de 1959 con 190,7 mm. En cambio, en Buñuel $(55,7 \mathrm{~mm}$ en 1991) siete meses han sido más lluviosos y el último de ellos en 1975.

Como se ha afirmado anteriormente en el comentario de la situación atmosférica general, en el mes de septiembre hubo dos períodos lluviosos distintos. En el mapa $n .^{\circ} 1$ se puede apreciar la dinámica atmosférica del día 3-9-91. En el mapa de $500 \mathrm{mb}$. se observa un embolsamiento frío de $-16^{\circ}$, situado al Oeste de Galicia y que abarca la mitad Occidental de la Península. Asimismo, un área de altas presiones se sitúa en las Islas Británicas.

En superficie se puede ver una situación muy parecida a la de las altas capas. El anticiclón se centra en el mismo sitio y en el centro de la $\mathrm{Pe}$ nínsula aparece un área de bajas presiones. Las masas de aire de superficie, dado el embolsamiento frío de altura, ascienden formando nubes de desarrollo vertical y tormentas.

Las tormentas afectan a toda Navarra y dan chubascos generales. EI corredor de la Barranca, situado en la parte occidental de Navarra, es el más lluvioso (Alsasua $37 \mathrm{~mm}$ ). A continuación los valles Cantábricos y los Pirineos Centrales (Artikutza 21,5 mm, Eugi 17,8 mm). En la cuenca de Pamplona, la Navarra Media y la Ribera llueve también, pero la cantidad recogida normalmente es inferior a los diez milímetros. 
Dia 3-9-91

12 h. (TMG.)
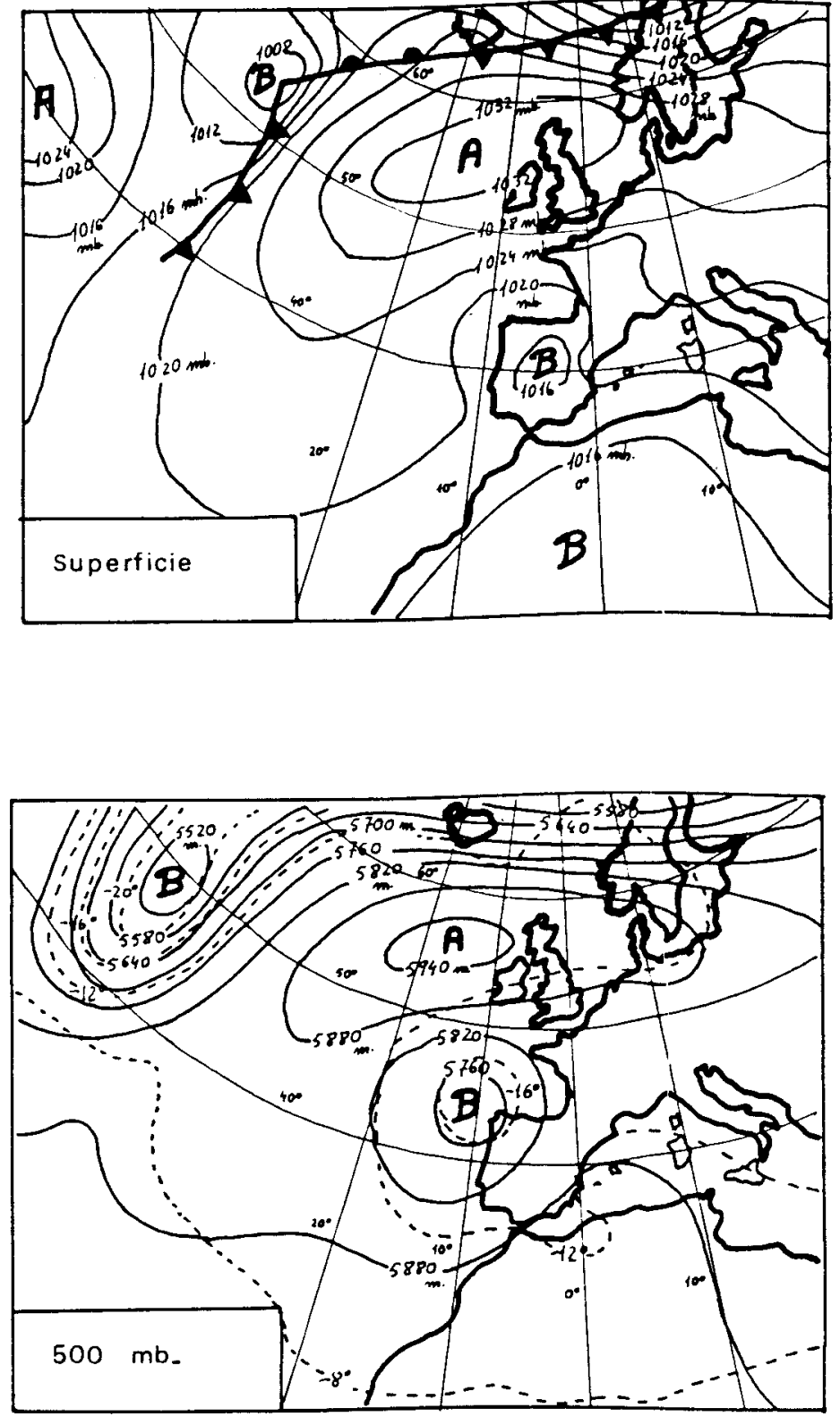

MAPA $n .^{\circ} 1$ 
Distinta situación, pero con el común denominador de lluviosa, fue la del día 25-9-91 dibujada en el Mapa $n .^{\circ}$ 2. En efecto, en la topografía de $500 \mathrm{mb}$. se observa la presencia de una circulación ondulada con la llegada de una vaguada de gran gradiente; la Península Ibérica está en el ramal de salida de la misma por lo que la inestabilidad es grande.

En superficie, la Península se encuentra en un área de bajas presiones, que van desde Islandia hasta el Norte de África, y rodeada de dos anticiclones, uno en el Atlántico y otro en la parte Oriental de Europa. Un frente frío barre la Península dando lugar a abundantes lluvias. Las masas de aire polares marítimas y húmedas, vienen desde las inmediaciones de Islandia y son muy inestables, porque se van recalentando por su base conforme se acercan a nuestras latitudes.

El aire frío que llega, penetra en cuña y levanta el cálido estancado, produciéndose chubascos por toda Navarra. El denominador común es altas precipitaciones de tormenta y normalmente por encima de los veinte milímetros en toda la Comunidad. Destacan como focos muy lluviosos Navarra Húmeda (Artikutza 55,4 mm, Santesteban $34,5 \mathrm{~mm}$ ), los Pirineos Centrales (Eugi $32,7 \mathrm{~mm}$ ) y algunas zonas marginales de la Ribera (Carcastillo $36 \mathrm{~mm}$, Yesa $25 \mathrm{~mm}$ ).

\section{UN OCTUBRE LLUVIOSO COMO LOS DE ANTAÑO}

Según los datos históricos octubre es en Navarra un mes típicamente otoñal caracterizado porque la influencia del verano va cediendo, lo cual se manifiesta en las temperaturas más típicas de otoño que del estío, como ocurría en septiembre.

Con respecto a las precipitaciones de octubre hay que afirmar que tradicionalmente han sido seguras, salvo en los años de sequía últimos, anteriores a 1991, que hemos padecido en la última década. En efecto, la bajada del frente polar hasta nuestras latitudes era una realidad en octubre, y los temporales de lluvia atravesaban Navarra aportando las beneficiosas lluvias.

Octubre de 1991 ha sido lluvioso y ha roto una cadena de octubres secos de años anteriores, y la circulación favorable de la atmósfera ha colaborado en que así sea. Se pueden distinguir varios períodos en el comportamiento dinámico de este mes.

Los siete primeros días de octubre de 1991 se caracterizaron por una circulación anticiclónica que lógicamente no dio lugar precipitaciones en Navarra. En efecto, un anticiclón se posiciona en el Atlántico al Oeste de 
Día 25-9-91

12 h. (TMG)
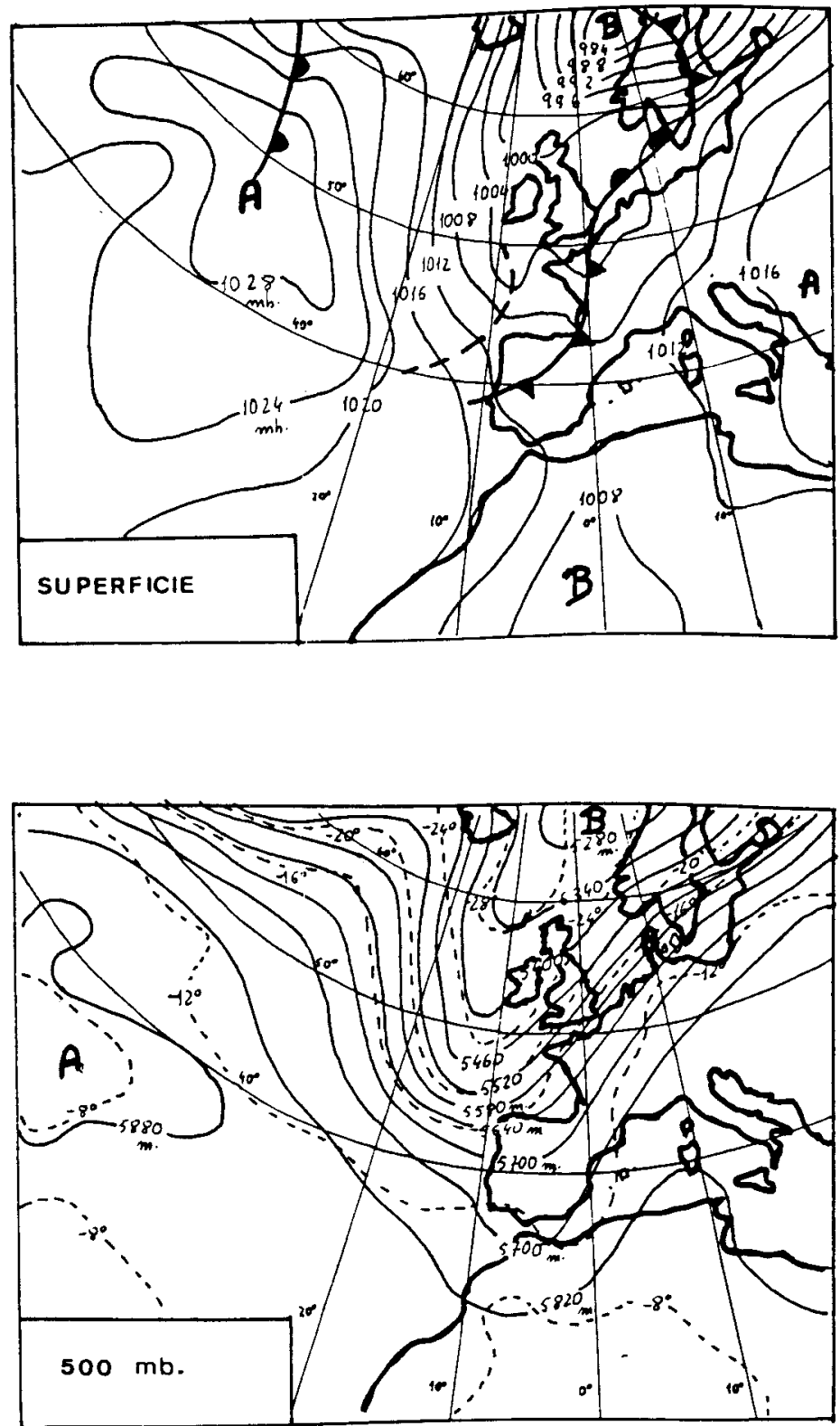

MAPA $n .^{\circ} 2$ 
Portugal y ejerce su radio de acción sobre la Península bloqueando la entrada de los frentes lluviosos por su flanco oriental. Este anticiclón se acaba convirtiendo en un puente de altas presiones que enlaza con otro centro situado en Europa Central.

Con este esquema la estabilidad está asegurada, si bien en algún momento llegan a originarse débiles precipitaciones en Navarra Húmeda, al crearse, algún día, una situación anticiclónica del Noroeste con extremos de frentes fríos que rozan nuestro territorio. También, el día cinco, se vuelven a repetir las precipitaciones en Navarra Húmeda y en los valles Pirenaicos por el paso de una vaguada, que deja aislada una gota fría en el Sur de Francia, y que, al trasladarse hacia Italia, no produce posteriormente precipitaciones. En definitiva y pese a estas excepciones, el anticiclón domina y ejerce su influencia sobre Navarra.

Desde el día ocho hasta el veinte, es decir a mediados, se puede distinguir un segundo período caracterizado por el paso de vaguadas que dan lugar a una inestabilidad y a las más altas precipitaciones registradas durante este mes. El día ocho, en el mapa de 500 milibares se observa una vaguada profunda con dos embolsamientos de -28 / que se extienden meridianamente desde Islandia hasta el Oeste de Portugal siguiendo el meridiano 15/ Oeste. Al día siguiente una gota fría se desprende de la misma y se sitúa al Oeste de Galicia y posteriormente se mueve por la Península, se instala sobre nuestra vertical, pasa al Cantábrico Oriental y a Bretaña y el día quince se transforma en una amplia vaguada que llega hasta el Norte de África.

Esta gota fría afecta a Navarra, sobre todo durante los días nueve y diez, ya que Navarra se encuentra en el frente de ataque de esta borrasca y las precipitaciones son generales e intensas en toda Navarra, siendo los observatorios de la Ribera más irrigados que los de Navarra Húmeda, pues las masas de aire vienen del Sur.

El esquema de altura se repite en superficie, puesto que una borrasca acompañada de frentes fríos asociados atraviesan Navarra. Los centros de las borrascas están próximos a Navarra: en el Oeste de Portugal, en el Cantábrico Oriental, en Bretaña.

A partir del día diecisiete la vaguada fría de altura da lugar a una gota fría que se posiciona en el Norte de África y que ya no afecta a nuestra Comunidad. Sin embargo una borrasca potente situada en Dinamarca produce algunas precipitaciones. Efectivamente, un anticiclón de orientación meridiana se extiende por el Atlántico, desde Islandia hasta las Canarias, y un centro de bajas presiones se sitúa al Sur de Escandinavia. Entre ambos centros de acción, masas de aire polares del Norte, que se ines- 
tabilizan al recalentarse por su base camino de Navarra, originan un descenso de temperaturas y precipitaciones, que van descendiendo de Norte a Sur de nuestra Comunidad.

A partir del día veinte y hasta el final, si bien se van a registrar precipitaciones, éstas van a ser de poca cuantía. Los primeros días un anticiclón abarca la Península y después se sucede el paso de vaguadas, pero a diferencia de las de mediados de octubre, éstas son poco profundas y con poco gradiente de presión, por lo que los resultados pluviométricos son escasos.

Por lo tanto y a modo de resumen, se han distinguido tres períodos dentro de este mes. El primero anticiclónico con escasas precipitaciones. El segundo, a mediados, caracterizado por el paso de vaguadas y ubicación de una gota fría sobre nuestra vertical, que es la que origina las altas precipitaciones. $Y$ finalmente, un tercer período caracterizado por la situación anticiclónica y el paso de vaguadas lejanas y de poca fuerza, que no dan apenas lluvias.

Las situaciones atmosféricas dominantes han sido las del Norte y las del Oeste que casi suponen el cuarenta por ciento de los días de octubre (Tabla II). Las primeras son las responsables de las altas precipitaciones en nuestra Comunidad, junto con las del Sudoeste, que representan algo más del doce por ciento, y que tuvieron lugar cuando la gota fría, a mediados, estuvo cerca de Navarra.

Con casi el diez por ciento figuran las situaciones del Nordeste, del EsteSudeste y del Oeste-anticiclónico, más bien anticiclónicas y con ausencia o con escasas precipitaciones. El resto de situaciones apenas si aparecen. La situación de anticiclón aparece con un porcentaje escaso y conviene aclarar que los días de altas presiones están anotados en otras casillas, pues por su flanco oriental pueden llegar a Navarra masas de aire del Norte, Nordeste, Este-Sudeste, etc, que se incluyen en esos apartados.

Estos tipos dominantes de circulación no van a producir tanta diferencia en la cantidad de lluvia entre las distintas comarcas navarras, como ocurría en septiembre, $y$ esto es debido al predominio de las situaciones de Sur procedentes de las gotas o vaguadas frías.

Los valles Cantábricos y los Pirenaicos son las zonas más irrigadas de Navarra. Los observatorios más lluviosos, con más de ciento cincuenta milímetros recogidos, se encuentran en los valles de Leitzarán y UrumeaAñarbe; zona de UrdaxZugarramurdi; alto Belate; Ilanada Espinal-Burguete-Roncesvalles; valle de Belagua; y valles de Salazar y Roncal. Así pues, no hay grandes diferencias con situaciones de gota fría entre Navarra 
Húmeda, más lluviosa, y las valles Pirenaicos (Artikutza $171,8 \mathrm{~mm}, \mathrm{Zu}$ garramurdi $179 \mathrm{~mm}$, Belate $189 \mathrm{~mm}$, Roncesvalles $152,5 \mathrm{~mm}$, BelaguaIsaba 171,9 mm, Esparza de Salazar 165,3 mm).

La explicación de estos resultados es muy sencilla. Las situaciones más lluviosas han sido del Sudoeste y los valles Pirenaicos ejercen un efecto pantalla ante esta circulación y resultan ser más lluviosos que los valles Húmedos. Con otras situaciones, como las del Norte, los resultados son al revés, y la suma de todo el mes compensa y da los resultados alcanzados. Conviene recordar que en estos casos influye en el mayor registro de precipitaciones, por una parte la altitud de los observatorios, y por otra la exposición de los mismos.

El resto de observatorios de los valles Cantábricos y Pirenaicos obtienen inferiores resultados, pero en todos los casos superan los cien milímetros (Betelu 129,5 mm, Sunbilla $123,7 \mathrm{~mm}$, Arizkun 106,5 mm, EugiEsteríbar 122,8 mm, Erro $129 \mathrm{~mm}$, Aribe 121,3 mm, Abaurrea Alta 133,6 $\mathrm{mm}$ ).

En este mes y con las citadas situaciones de Sur los resultados anteriores no fueron muy diferentes a los del corredor de la Barranca y a los obtenidos por los valles meridionales húmedos, que se situaron todos ellos próximos a los ciento cincuenta milímetros (Iraitzoz $147,6 \mathrm{~mm}$, Olague $143,4 \mathrm{~mm}$, Belzunce $139,7 \mathrm{~mm}$, Alsasua 147,8 mm). En la cuenca de Pamplona la cantidad recogida se aproxima a los cien milímetros (Pamplona-Obs. $106,4 \mathrm{~mm}$, Noain $83,5 \mathrm{~mm}$, llundain $88,7 \mathrm{~mm}$ ). En los lugares altos, la lluvia fue superior (Goñi $158 \mathrm{~mm}$ ) y hacia el Este las precipitaciones disminuyeron (Monreal 56,9 mm).

Con este tipo de situaciones la Navarra Media suele ser lluviosa, sobre todo los lugares próximos a las sierras Exteriores, que en algunos casos se sitúan por encima de los cien milímetros e incluso cercanos a los ciento cincuenta, todo esto debido a la proximidad a estas montañas que realizan un efecto de pantalla con situaciones del Sur (Larraona 140,4 mm, Galbarra $142 \mathrm{~mm}$, Igúzquiza 132,7 mm, Olóriz $105 \mathrm{~mm}$, Lerga $106 \mathrm{~mm}$ ). El resto de los observatorios obtiene cantidades que se aproximan a los cien milímetros (Cáseda $96,7 \mathrm{~mm}$, Olite $99 \mathrm{~mm}$, Yesa $87,5 \mathrm{~mm}$, Alloz 105,3 $\mathrm{mm}$, Puente la Reina $88,6 \mathrm{~mm}$ ).

Las precipitaciones más bajas se registraron en la Ribera Navarra, con cantidades próximas a los cincuenta milímetros, siendo más lluviosa la zona de Carcastillo (Carcastillo 79,6 mm, Caparroso $64 \mathrm{~mm}$, Fitero 48,8 $\mathrm{mm})$. En el extremo Sur, Buñuel obtuvo la cantidad más escasa $(35,9$ $\mathrm{mm}$ ).

La cantidad de precipitación de octubre de 1991 ha sido muy parecida a la registrada en las series históricas, es decir normal en cuanto a la 
pluviometría. En Navarra Húmeda los resultados son algo inferiores a la media (Santesteban 119,3 mm en 1991 y $136,6 \mathrm{~mm}$ media de las series históricas). En los valles Pirenaicos el año 1991 se ha situado ligeramente por encima de la media (Abaurrea Alta 133,6 mm en 1991 y media histórica $121,5 \mathrm{~mm}$ ), si bien en los Pirineos Centrales la lluvia de este año ha sido algo inferior (Eugi-Esteríbar 122,8 mm y $162 \mathrm{~mm}$ respectivamente).

En el corredor de la Barranca, en la cuenca de Pamplona, en la Navarra Media y en la Ribera, octubre de 1991 ha sido más lluvioso que la media histórica (Alsasua 147,8 mm y $104 \mathrm{~mm}$; Pamplona-Observatorio 106,4 mm y $76,4 \mathrm{~mm}$; Yesa $87,5 \mathrm{~mm}$ y $77,9 \mathrm{~mm}$; Carcastillo $79,6 \mathrm{~mm}$ y $34,1 \mathrm{~mm}$ ).

Por lo tanto, un mes normal en Navarra Húmeda y en los valles $\mathrm{Pi}$ renaicos, y más lluvioso de lo normal en el corredor del Araquil, en la cuenca de Pamplona, en la Navarra Media y en la Ribera, pero con la peculiaridad de interrumpir los octubres secos de los últimos años.

Se han elegido, para su estudio dos situaciones lluviosas totalmente diferentes que tuvieron lugar en octubre de 1991. Los días nueve y diez de octubre fueron los que más precipitaciones registraron en la Comunidad Navarra (Mapa $n .{ }^{\circ} 3$ ). En la topografía de 300 milibares el día nueve se observa una gota fría situada junto a Galicia y que afecta a nuestra área de estudio, pues se encuentra en la rama de salida o en el frente de ataque de la misma.

La corrriente en chorro es fuerte de componente Norte en el Atlántico, siguiendo el meridiano 20/ Oeste y del Sudoeste en la Península y en Navarra. Las masas de aire son polares procedentes de las altas latitudes, pero que se han ido recalentando e inestabilizando a su paso por el Atlántico por latitudes templadas y subtropicales. Estas masas de aire vienen cargadas de humedad en su trayectoria oceánica. El día diez persiste con fuerza el embolsamiento frío y las masas de aire que llegan a Navarra siguen siendo potentes y del Sudoeste.

La presencia de la gota fría en altura, de mucha potencia y gradiente, de $-24^{\circ}$ de temperatura en octubre en la topografía de 500 milibares; el posicionamiento de una borrasca también poderosa en superficie con 996 $\mathrm{mb}$. en su centro; los frentes cálidos y fríos que atraviesan Navarra; la llegada de masas de aire del Sudoeste húmedas e inestables; y finalmente la situación y el relieve de nuestra Comunidad van a explicar las altas precipitaciones registradas estos días.

Sumando las precipitaciones obtenidas en los dos días, se comprueba que los lugares más lluviosos son tres: los Altos Pirineos Orientales, porque suponen una nueva pantalla condensadora de humedad ante las masas de aire del Sudoeste; el corredor de la Barranca, situado a barlovento 


\section{Dias 9 y 10-10-91 \\ 12h. (TMG)}
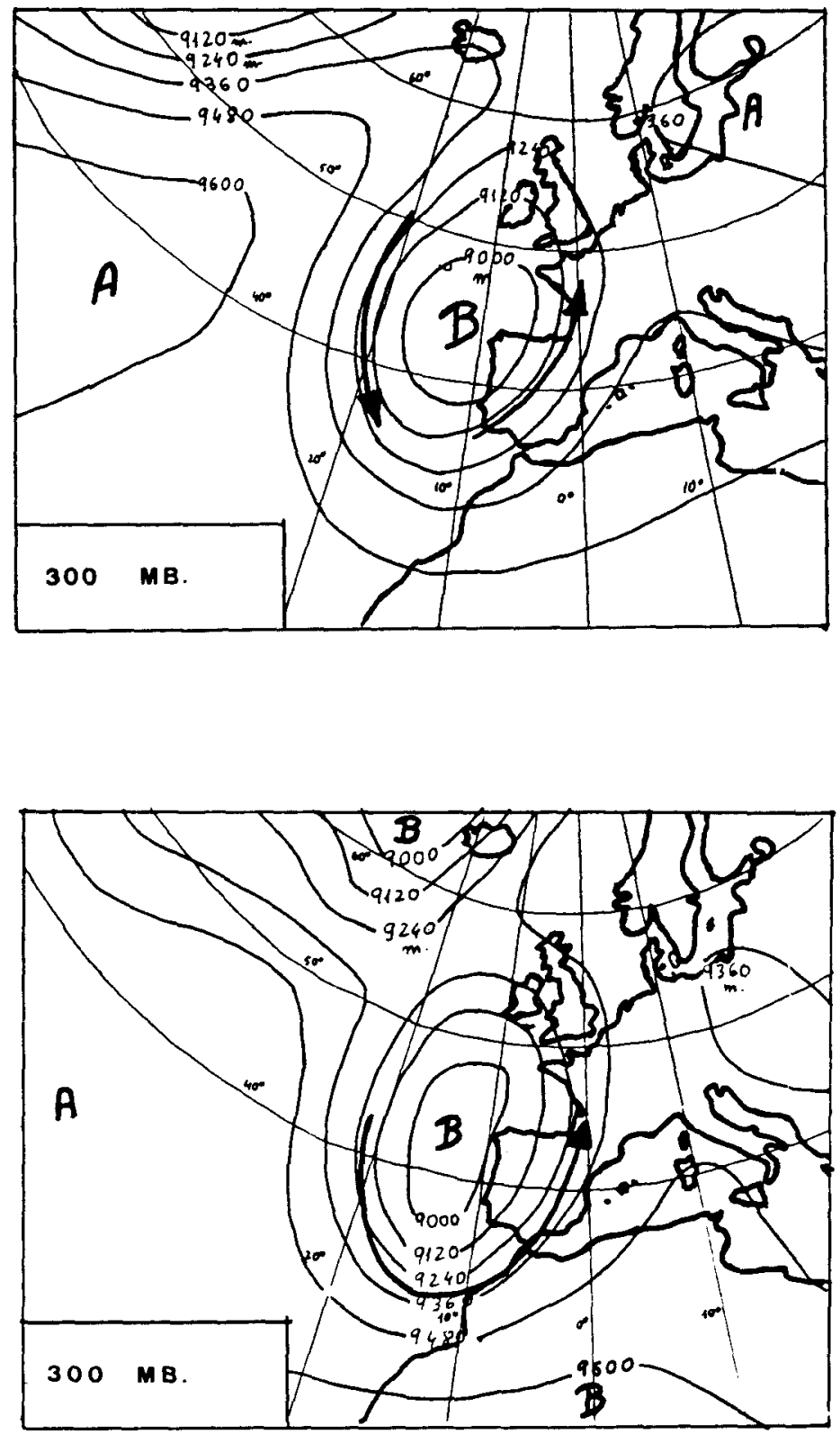

MAPA $n .^{\circ} 3$ 
de la sierra de Aralar, auténtica muralla ante el aire meridional; y la cuenca de Pamplona, bien situada a las advecciones de procedencia meridional (Abaurrea Alta $89,6 \mathrm{~mm}$, Alsasua $82 \mathrm{~mm}$, Pamplona-Obs. $74 \mathrm{~mm}$ ).

El papel del relieve es fundamental, cuando se trata de gotas frías, pues se producen continuos ascensos y descensos de masas de aire, 0 lo que es lo mismo mayores condensaciones. Los Pirineos Centrales y la regata del Bidasoa resultan también muy irrigados, por estar junto a montañas, en el primer caso el macizo de Quinto Real y en el segundo los montes del Bidasoa y macizo de Cinco Villas, que realizan el papel de pantallas de humedad (Eugi-Esteríbar $64 \mathrm{~mm}$ y Santesteban $63,2 \mathrm{~mm}$ ). No se quedan muy atrás en cuanto a cantidad de lluvia recogida, los lugares de Navarra Media situados junto a las sierras Exteriores, que experimentan condensaciones importantes (Alloz $59,7 \mathrm{~mm}$ y Yesa $50 \mathrm{~mm}$ ).

Por el contrario, los Valles Húmedos, los más lluviosos de Navarra recogen cantidad inferior, pues se encuentran mal situados, a sotavento de la cadena Divisoria y del macizo de Cinco Villas (Artikutza 41, $5 \mathrm{~mm}$ ). Sorprende que la Ribera Navarra alcance resultados parecidos (Carcastillo $40,5 \mathrm{~mm}$ ).

Estas potentes gotas frías, que se posicionan al Oeste de la Península resultan muy lluviosas por las zonas que se encuentran en la línea de penetración; me estoy refiriendo a Andalucía, Castilla-la Mancha y Madrid (Jerez-Aeropuerto $134 \mathrm{~mm}$, Toledo $37 \mathrm{~mm}$, Madrid-Ciudad Univ. $46 \mathrm{~mm}$ ).

Menos lluviosa fue la situación atmosférica de finales de octubre (Mapa $n .^{\circ} 4$ ). En efecto, el día 28 , en el mapa de 500 milibares se observa una situación del Oeste de escaso gradiente, con una temperatura entre $-16^{\circ}$ y $-20^{\circ}$. Una borrasca a niveles altos se encuentra a la altura del Canal de la Mancha. En superficie, Navarra se ubica entre una borrasca situada a la altura de Bretaña, reflejo de la de altura, y un anticiclón de poca potencia. Un frente frío del Oeste barre Navarra y da precipitaciones moderadas.

Navarra Húmeda es la zona más irrigada (Artikutza $7,8 \mathrm{~mm}$ ). El resto de Navarra no alcanza los cinco milímetros, disminuyendo ligeramente la cantidad recogida de Norte a Sur. Se trata de lluvia fina, tipo txirimiri propia de situaciones del Oeste de débil gradiente.

\section{UN NCYIEMERE CON ABUNDANTES PRECIPITACIONES}

Noviembre es un mes tradicionalmente lluvioso en Navarra, según las series estadísticas de muchos años. Es un mes bastante más seguro en 
Día 28-10-91

12 h. (TMG)
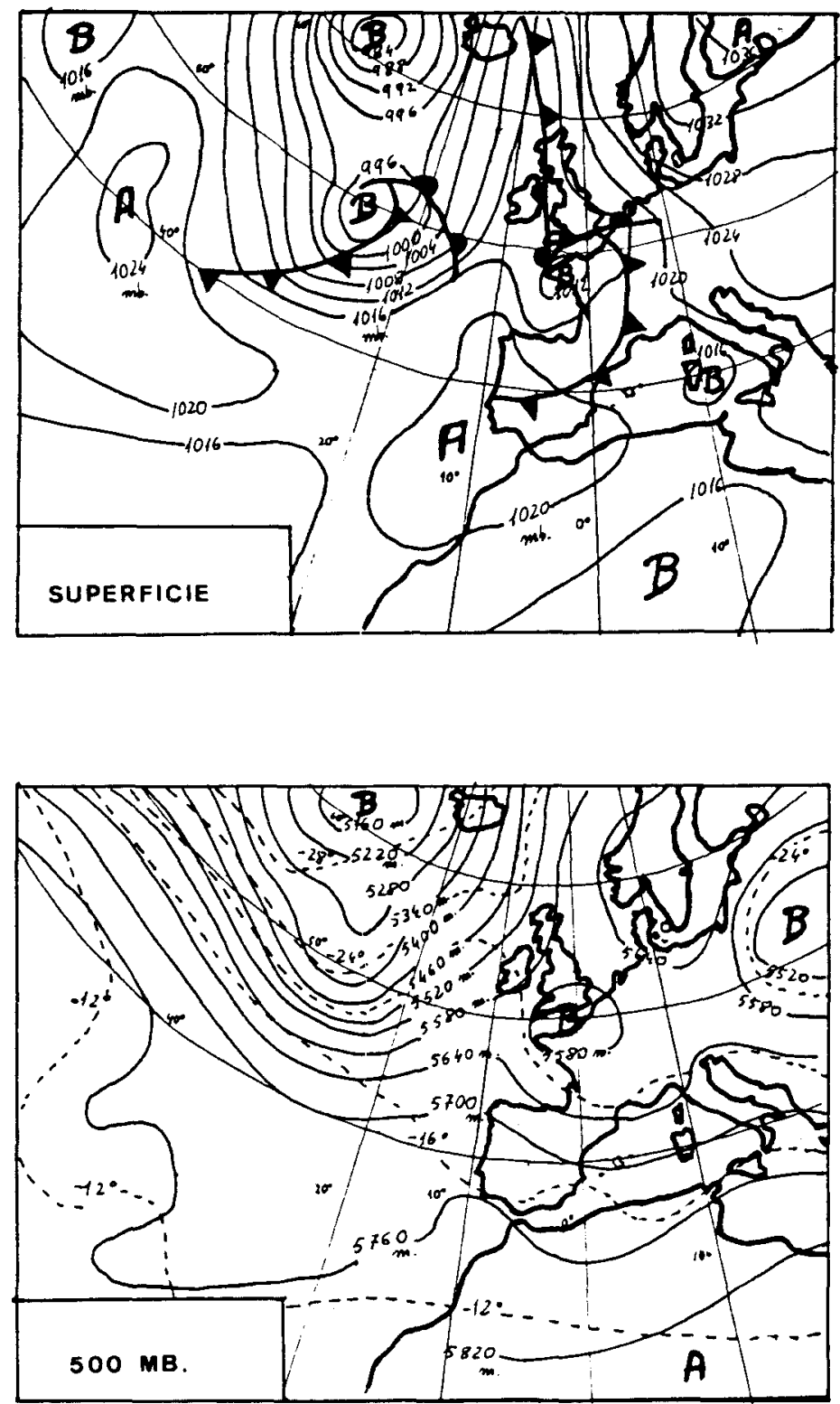

MAPA n. ${ }^{\circ} 4$ 
precipitaciones que octubre y septiembre. La bajada del frente polar y el paso de los temporales del Oeste se suceden la mayor parte de los años. Sin embargo los últimos noviembres han sido bastante secos y este de 1991 ha roto una secuencia de noviembres con pocas lluvias.

La dinámica atmosférica de estos días explica las altas lluvias. Tres períodos se pueden distinguir en este mes en cuanto a las situaciones atmosféricas. El primero de ellos, que comprende los seis primeros días, se caracteriza por el dominio de una borrasca potente, que afecta a la Comunidad Navarra, pese a su alejamiento, pues se posiciona en Islandia, Noruega, Norte de Inglaterra.

En superficie, aparecen situaciones zonales, meridianas y submeridianas, acompañadas de sistemas frontales cálidos y fríos. En altura la corriente en chorro que circula por latitudes más septentrionales acaba por atravesar Navarra el día cinco, mediante un ramal del Sur.

Se trata de días lluviosos en Navarra Húmeda, en los valles Pirenaicos $y$ en el corredor de la Barranca. En el resto las precipitaciones son moderadas y escasas, estableciéndose un gradiente frecuente de disminución Norte-Sur y Oeste-Este.

Después de esta primera semana hay un paréntesis seco, si bien se recogen moderadas lluvias en el Norte, debido al posicionamiento del anticiclón en nuestras latitudes. Sin embargo una nueva borrasca situada en Escocia vuelve a afectar, sobre todo a la parte Norte de Navarra.

El segundo período tiene lugar desde los días doce a veintiuno de noviembre y se caracteriza por las abundantes precipitaciones que se registran en Navarra, que dan lugar a riadas en nuestra Comunidad y a las primeras nevadas del año, que cierran algunos puertos de montaña.

Este período se va a caracterizar por la presencia de un pasillo de borrascas, que se extiende desde Terranova hasta Europa Central. La más cercana a Navarra se sitúa en el Centro de Inglaterra y se mueve el día diecinueve hacia las inmediaciones de la capital francesa; el día veinte se posiciona junto al golfo de Génova; y el veintiuno en el Centro-Sur de Francia.

La corriente en chorro, que en los primeros días sigue latitudes algo más septentrionales, concretamente Centro de Francia, acaba profundizándose y sigue trayectorias más meridionales y próximas a nuestra geografía. El día quince, muy lluvioso en Navarra, la corriente en chorro es del Noroeste en el Centro de la Península; el día dieciséis del mismo componente atraviesa la parte Sur del valle del Ebro; el día diecinueve es del Noroeste en Galicia; y el día veinte del Norte en Asturias. 
En superfice, el gradiente es fuerte y los frentes fríos, algunos de ellos de amplio radio de acción, atraviesan Navarra. Los días de precipitación más intensa, los centros de las borrascas de superficie se sitúan en posiciones cercanas al territorio de Navarra. Las situaciones atmosféricas fueron principalmente del Norte y del Noroeste, es decir las que normalmente son más lluviosas en Navarra.

Finalmente el tercer período, que abarca hasta el final del mes, se caracteriza por la procedencia de situaciones poco propicias para registrar precipitaciones. Se suceden así anticiclones de bloqueo sobre la Península, altas presiones que se extienden por el Centro de Europa y África con situaciones del Sudoeste, todas ellas secas en Navarra. Una borrasca fija se llega a centrar en Canarias y envía masas de aire de componente Sur, cuyo resultado pluviomético es escaso. Llueve ligeramente algún día, pero con carácter moderado.

Al mirar la Tabla // se aprecia que las situaciones de noviembre de 1991 son ya propias de otoño. Destaca la circulación del Oeste, con sus variantes Noroeste y Sudoeste, que juntas suponen más de la mitad de los días de noviembre. Las situaciones del Norte, muy lluviosas sobre todo en el Norte de Navarra, alcanzan el diez por ciento. Finalmente es destacar la situación de anticiclón centrado que supone más del veinte por ciento de los días de noviembre. Por lo tanto, presencia de circulación muy propicia para las lluvias.

Las precipitaciones fueron elevadas en toda la Comnunidad durante el mes de noviembre de 1991. Los valles Cantábricos, los Pirenaicos Centrales, la llanada Espinal-Burguete-Roncesvalles y el valle de Belagua fueron los focos más lluviosos, con una precipitación total por encima de los trescientos milímetros (Goizueta $306,5 \mathrm{~mm}$, Leitza $389,9 \mathrm{~mm}$, Areso 359,1 $\mathrm{mm}$, Lesaka $360 \mathrm{~mm}$, Bera $356 \mathrm{~mm}$, Sunbilla $326,1 \mathrm{~mm}$, Zugarramurdi 331 $\mathrm{mm}$, Roncesvalles $345,4 \mathrm{~mm}$, Belagualsaba $358,2 \mathrm{~mm}$ ).

El observatorio de Artikutza, bien orientado a los flujos del Cantábrico, superó los cuatrocientos milímetros de precipitación. En los puertos de Belate y Azpírotz, debido a la altitud, se superaron también los trescientos milímetros (Belate $318,5 \mathrm{~mm}$, Azpírotz $328,3 \mathrm{~mm}$ ). Fuera de estos valles, las montañas de las sierras Exteriores, pese a su latitud más meridional, y al desecamiento de las masas nubosas después de atravesar las montañas más septentrionales, recogen más de trescientos milímetros (Urbasa $306 \mathrm{~mm}$, Goñi $300 \mathrm{~mm}$ ).

El resto de los valles Pirenaicos, los valles meridionales húmedos y el corredor de la Barranca superan los doscientos milímetros de precipitación en este mes de noviembre (Eugi-Esteríbar 267,2 mm, Erro $231 \mathrm{~mm}$, Aribe 
$266 \mathrm{~mm}$, Urzainqui $270 \mathrm{~mm}$, Iraitzoz $238 \mathrm{~mm}$, Olague $264,5 \mathrm{~mm}$, Belzunce $218,4 \mathrm{~mm}$ ). Sin duda, su situación al Sur de la cadena Divisoria significa una merma en la cantidad recogida, si bien todavía las situaciones lluviosas son potentes en esta zona. Asimismo algunos lugares elevados de la Navarra Media como la Amescoa Alta y el valle de Lana obtienen parecidas precipitaciones (Larraona 232,8 mm, Galbarra 213,5 mm).

Las cuencas de Pamplona y de Lumbier-Aóiz y la Navarra Media registran normalmente más de cien milímetros de precipitación (PamplonaObserv. $119 \mathrm{~m}$, llundain 126,5 mm, Monreal 114,1 mm, Alloz 110,3 mm, Yesa $112,2 \mathrm{~mm}$, Lerga $133 \mathrm{~mm}$ ). Las precipitaciones disminuyen hacia el Sur y hacia el Este y aumentan con la altitud. Las masas de aire del Norte y del Noroeste se ven frenadas por la cadena Divisoria y por las sierras Exteriores, siendo los resultados pluviométricos más reducidos en esta zona. Finalmente en la Ribera Navarra apenas llovió y es de resaltar la situación del valle del Ebro, alejada de la influencia de las situaciones lluviosas septentrionales, al que llegan las masas de aire secas (Carcastillo $75,7 \mathrm{~mm}$, Monteagudo 10,9 mm, Buñuel $14,3 \mathrm{~mm}$, Fitero $15,2 \mathrm{~mm}$ ).

Si se consultan las series históricas se puede comprobar que noviembre ha sido de los más lluviosos desde 1940 . Santesteban $(273,5 \mathrm{~mm}$ en noviembre de 1991 y $186,8 \mathrm{~mm}$ media de series históricas) ha registrado siete noviembres más lluviosos que éste y no llovía tanto desde 1975. Abaurrea Alta en los valles Pirenaicos (222,1 mm en noviembre de 1991; $150,2 \mathrm{~mm}$ media series históricas) tan sólo ha registrado cinco noviembres más lluviosos, el último de ellos en 1984. En el valle de la Barranca, Alsasua (253,7 mm en 1991 y $146 \mathrm{~mm}$ media histórica) registra el mes más lluvioso desde 1975 y en las series históricas se observa tan sólo cinco años más lluviosos.

En la cuenca de Pamplona noviembre de 1991 también superó la media histórica (Pamplona-Observ. $119 \mathrm{~mm}$ en 1991 y 90,6 mm media histórica); aquí se han anotado doce noviembres más lluviosos y el último el del año 1984. Resultados parecidos se registran en Yesa $(112,2 \mathrm{~mm}$ en 1991 y $77,6 \mathrm{~mm}$ en las series históricas). Finalmente en Carcastillo se han obtenido ocho noviembres más lluviosos $(75,7 \mathrm{~mm}$ en 1991 y $128,9 \mathrm{~mm}$ en las series históricas).

Vamos a continuación a estudiar detenidamente dos situaciones muy lluviosas de noviembre. En el Mapa $n .^{\circ} 5$ se observa el temporal de lluvias de los días cuatro a siete de noviembre. La Península lbérica se encuentra entre dos centros de acción bien definidos: un anticiclón Atlántico extendido meridianamente desde Islandia hasta las Canarias y un sistema de borrascas, de la misma orientación, que se alarga desde Escandinavia hasta el Mediterráneo. 
Cías 4 a 7-11-91

Superficie 6 y $18 \mathrm{~h}$.

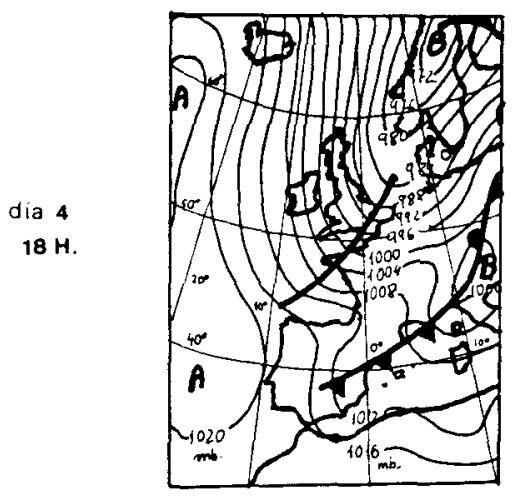

día 5

$6 \mathbf{H}$.
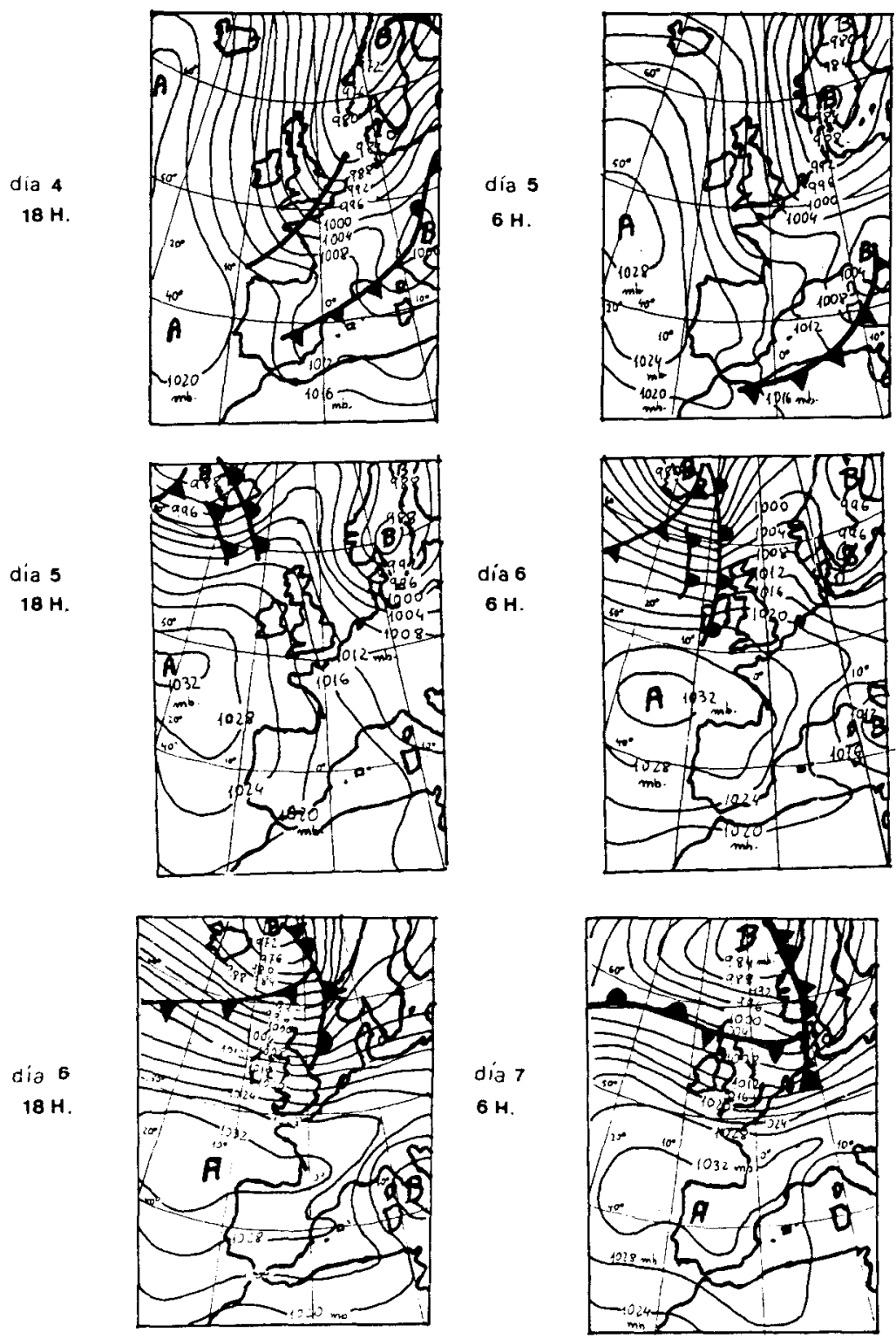

MAPA $n .^{\circ} 5$ 
Entre ambos centros de acción circulan masas de aire de componente Norte, marítimo polares que se han recalentado y humedecido en su trayectoria hacia nuestra Comunidad, dando cuantiosas lluvias. El anticiclón del Atlántico, poco a poco, va penetrando en Navarra, pero la inestabilidad sigue hasta el día seis, pues por el flanco oriental continúan llegando masas de aire del Norte. Finalmente el día siete acaba por imponerse el anticiclón y cesan las precipitaciones en Navarra, salvo lluvias inapreciables que persisten en la cornisa Cantábrica.

Con esta situación septentrional las máximas precipitaciones se registran en los valles de Leitzarán, Araitz y Urumea-Añarbe, bien orientados a los flujos del Norte, que son retenidos y obligados a ascender por el macizo de Cinco Villas (Artikutza 79,1 mm durante los días 4 a 7). Los valles Pirenaicos Centrales también son muy lluviosos con esta situación (Eugi-Esteribar $61,7 \mathrm{~mm}$ ). La regata del Bidasoa y los Pirineos Orientales registran inferiores precipitaciones (Santesteban $48,6 \mathrm{~mm}$ y Abaurrea Alta $48 \mathrm{~mm}$ ); en el primer caso la sombra pluviométrica con respecto al macizo de Cinco Villas y en el segundo, los Pirineos, explican este descenso. El corredor de la Barranca fue lluvioso (Alsasua $39,8 \mathrm{~mm}$ ).

La cuenca de Pamplona, la Navarra Media y la Ribera obtienen pocas precipitaciones, poniendo una vez más de manifiesto el poder de la cadena Divisoria con respecto a las masas de aire del Norte (PamplonaObs. $8,1 \mathrm{~mm}$, Alloz 9,4 mm, Carcastillo $9,6 \mathrm{~mm}$ y Fitero $2,8 \mathrm{~mm}$ ). Los frentes del Norte llegan bastante secos a la cuenca del Ebro y si bien dan lugar a precipitaciones, éstas son escasas.

Los días trece a veinte de noviembre fueron lluviosos en Navarra (Mapa $\left.n .{ }^{\circ} 6\right)$. La corriente en chorro se encuentra situada en posiciones meridionales y afecta de lleno a nuestra Comunidad. Se suceden situaciones del Noroeste, Norte y Oeste que son muy lluviosas. Algunos días se produjeron fuertes aguaceros, destacando el día trece, debido al paso de la primera vaguada; el día quince, en que aparece una situación del Noroeste con fuerte gradiente y chorro atravesando Navarra; el día diecinueve, porque hay una vaguada profunda sobre nuestro territorio; y el día veinte por una situación del Norte con chorro de la misma procedencia y próximo a Navarra.

Las lluvias fueron intensas durante estos ocho días sobre todo en $\mathrm{Na}$ varra Húmeda, en los valles Pirenaicos y en el corredor de la Barranca (Artikutza 329,3 mm, Santesteban $208 \mathrm{~mm}$, Eugi $183 \mathrm{~mm}$, Abaurrea Alta $154,1 \mathrm{~mm}$ y Alsasua $182,2 \mathrm{~mm}$ ). La situación de estas comarcas con respecto a las advecciones septentrionales, la inestabilidad de las masas de aire polares y la buena situación al pie de los macizos de Cinco Villas, Quinto Real y montes Pirineos, explican estos resultados. 
Estudio del otoño lluvioso de 1991 en Navarra

Dias 13 a 20-11-91 $300 \mathrm{mb} .-12$ h.(TMG.)

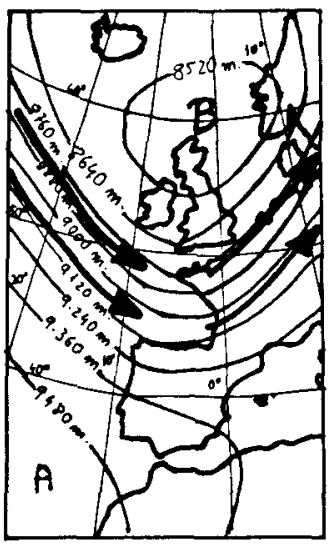

13

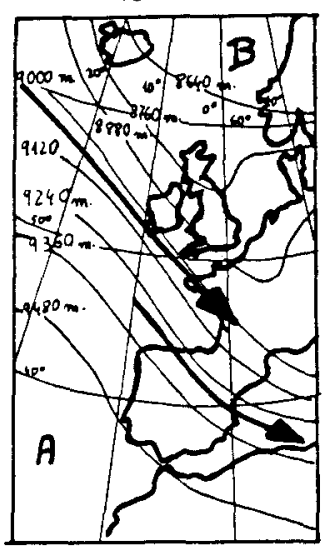

16

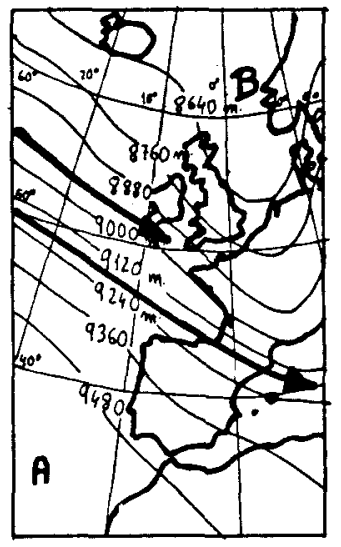

14

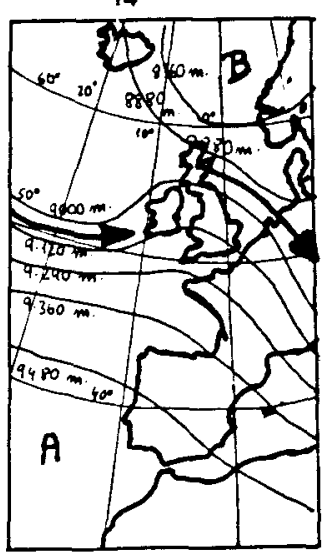

17

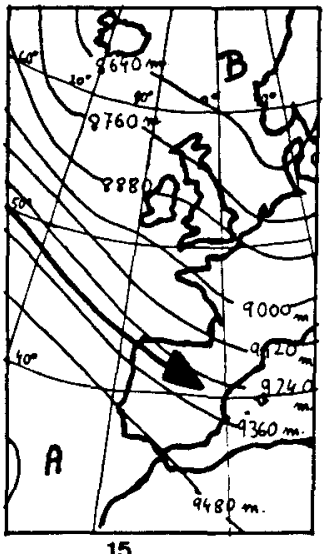

15

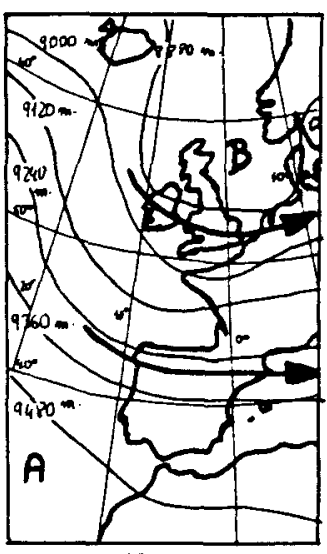

18
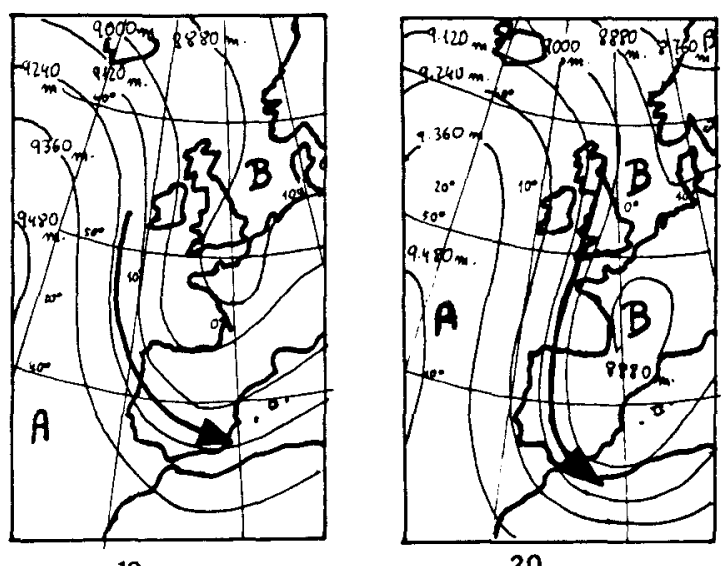

MAPA $n .^{\circ} 6$ 
En la cuenca de Pamplona, la Navarra Media y la Ribera la lluvia también fue importante, pero con diferencias apreciables, debido a su situación meridional con respecto a las pantallas pluviométricas de la cadena Divisoria y sierras Exteriores (Pamplona-Obs. 92,2 mm, Yesa 73,2 mm y Carcastillo $57 \mathrm{~mm}$ ). En el extremo Sur de Navarra estos temporales originaron pocas lluvias (Fitero $7 \mathrm{~mm}$ ).

Estas altas precipitaciones en tan pocos días produjeron fuertes crecidas de los ríos en algunas comarcas de Navarra. El Arga, el Ultzama, el Arakil, el Irati y el Bidasoa bajaban con aguas altas desde su nacedero, saliéndose en algunos lugares. En Pamplona llegó a sumergir las pasarelas de la Magdalena y la presa de San Pedro. Asimismo llegaron las primeras nevadas a los Pirineos, en algunos de cuyos puertos era necesario el uso de cadenas. Los embalses aumentaron considerablemente su capacidad.

\section{OTOÑO DE LOS MÁS LLUVIOSOS DE LAS SERIES HISTÓRICAS}

La dinámica atmosférica favorable y las características locales y latitudinales de Navarra dieron lugar a uno de los otoños más lluviosos en nuestra Comunidad y además supuso un peréntesis lluvioso entre los últimos otoños secos que habíamos padecido.

$Y$ las situaciones atmosféricas durante este otoño no fueron ajenas a estos resultados lluviosos. En la Tabla /I se observa el procentaje de frecuencias de cada tipo de situación. Las más frecuentes fueron las situaciones del Oeste, que superaron el quince por ciento, y que normalmente son lluviosas en Navarra, si tienen cierto gradiente. La circulación anticiclónica seca supuso más del catorce por ciento, pero las bajas o gotas frías sobre nuestro territorio, muy lluviosas, alcanzaron el quince por ciento. Y no sólo eso, sino que la circulación del Noroeste, la del Sudoeste y la del Norte, que originan abundantes lluvias alcanzaron resultados cercanos al diez por ciento. Por lo tanto, si sumamos las situaciones que suelen ser inestables en nuestra Comunidad (Oeste, Bajas frías, Noroeste, Norte y Sudoeste) se alcanza el sesenta por ciento, o sea casi los dos tercios de los días fueron inestables, resultados que explican las altas lluvias.

La Tabla III nos da una idea de la efectividad de cada una de las situaciones a la hora de aportar precipitaciones durante este otoño de 1991. Las del Norte, que fueron de fuerte gradiente, resultaron las más lluviosas en toda la Comunidad. En los valles Húmedos y Pirenaicos Centrales y en el corredor de la Barranca aportaron más del treinta por ciento 
TABLA III. PRECIPITACIÓN Y SITUACIÓN ATMOSFÉRICA

\begin{tabular}{|c|c|c|c|c|c|c|c|c|c|c|}
\hline & N. & NE. & $\begin{array}{l}\text { S/ } \\
\text { SW. }\end{array}$ & W. & W/A & NW. & BJ. & BT. & PB. & ANT. \\
\hline Artikutza & 32,5 & 4,3 & 4,6 & 16,6 & 1,2 & 26,3 & 12,9 & - & 1,4 & 0,2 \\
\hline Eugi-Est. & 30,1 & 5,3 & 13,8 & 16,2 & 0,9 & 20,3 & 7,7 & 1,6 & 3,2 & 0,1 \\
\hline Abaurrea A. & 19,5 & 5,4 & 17,4 & 22,6 & 0,6 & 15,8 & 10,7 & 3,5 & 3,4 & 0,3 \\
\hline Alsasua & 30,6 & 4,9 & 15,8 & 20,4 & 0,9 & 11,4 & 12,9 & 0,4 & 2,5 & 0 \\
\hline Pamplona-O. & 23,8 & 1,8 & 32,9 & 31,1 & 0,7 & 11,8 & 10,1 & 2,1 & 3,6 & 0 \\
\hline Yesa & 23,3 & 1,8 & 16,5 & 19,9 & 0,2 & 17,5 & 19,3 & 1,2 & 0,3 & 0 \\
\hline Fitero & 19,6 & 0,8 & 32,5 & 8,7 & 0,3 & 0,6 & 4,1 & 0,2 & 32,7 & 0 \\
\hline
\end{tabular}

N: Norte; NE.: Nordeste; S/SW.: Sur/Sudoeste; W.: Oeste; W/A.: Oeste-Anticiclónico; NW.: Noroeste; BJ.: Baja fría; BT.: Baja Térmica; PB.: Pantano Barométrico; ANT.: Anticiclón.

de la cantidad total de lluvia; y en el resto de Navarra, cuenca de Pamplona, Pirineos Orientales, Navarra Media y Ribera, si bien fueron menos lluviosas, en todos las zonas se aproximaron al veinte por ciento.

Sin duda, la posición latitudinal de Navarra, junto al Cantábrico Oriental, en el Norte de la Península, bien orientada a los flujos del Norte, es óptima para obtener altos registros lluviosos. Los valles Cantábricos y Pirenaicos Centrales son muy irrigados con esta circulación, pues las masas de aire septentrionales se ven obligadas a estancarse junto a los macizos de Cinco Villas y Quinto Real, produciendo fuertes chubascos. Por el contrario, los valles Pirenaicos Orientales, a sotavento de los Pirineos, son menos lluviosos, al igual que la cuenca de Pamplona, que se encuentra al Sur de la cadena Divisoria. Navarra Media y Ribera, situadas en la parte meridional de las sierras Exteriores, son poco lluviosas con esta situación.

Algo parecido sucede con las situaciones del Noroeste, que ven disminuir las lluvias de Norte a Sur por el efecto del relieve. En esta ocasión las lluvias del Noroeste fueron menos efectivas que las anteriores, representando más del veinte por ciento en los valles Cantábricos y Pirenaicos Centrales; más del quince en los Pirineos Orientales y Navarra Media; más del diez por ciento en la cuenca de Pamplona y en el corredor de la Barranca; y fueron secas en la Ribera.

Lo contrario sucede con la circulación del Sudoeste que aporta numerosas lluvias en la cuenca de Pamplona y en la Ribera, algo menos en la Navarra Media y en los Pirineos, y muy poco en los valles Cantábricos. Otra vez el factor relieve explica estos resultados, pues para cuando llegan estas masas de aire al Cantábrico han tenido que atravesar 
varias pantallas pluviométricas (sierras Exteriores, cadena Divisoria) y se han desecado bastante.

La circulación del Oeste aportó numerosa lluvia en Navarra, suponiendo en la cuenca de Pamplona más del treinta por ciento del total de lluvia, cifras cercanas al veinte por ciento en la Navarra Media, corredor del Barranca y Pirineos Orientales, y más del quince en el resto, salvo en la Ribera.

Finalmente, las bajas frías suelen ser lluviosas, si nuestro territorio se encuentra en el frente de ataque de las mismas. La aportación fue inferior a las anteriores situaciones, destacando las de Navarra Media. Hay que comentar el caso curioso de Fitero, en la Ribera Navarra, que obtuvo casi un tercio del total de lluvia con la situación de pantano barométrico, debido a las intensas tormentas que tuvieron lugar con este tipo de situación.

La cantidad de lluvia recogida durante el otoño de 1991 fue muy alta y así se pone de relieve en el análisis de los datos totales de precipitación por comarcas (Gráficos 1 a 5). Los valles Cantábricos fueron los más lluviosos de Navarra y en todos los observatorios se registraron más de quinientos milímetros de precipitación (Gráfico $n .^{\circ} 1$ ). El valle del UrumeaAñarbe fue el más irrigado con más de novecientos milímetros, cantidad muy superior a las medias históricas (Artikutza $910,2 \mathrm{~mm}$ en el otoño de 1991 y $698 \mathrm{~mm}$ en las series históricas).

Por encima de los setecientos milímetros resultaron ser focos muy lluviosos el valle de Leitzarán, el bajo Bidasoa y la zona de Urdax-Zugarramurdi, por la acción del efecto pantalla de los macizos de Cinco Villas y Quinto Real (Goizueta 719,3 mm, Leitza 773,7 mm, Areso 722,6 mm, Bera $725,7 \mathrm{~mm}$, Zugarramurdi $788 \mathrm{~mm}$ ). También el alto Azpírotz, en la cadena Divisoria, superó dicha cifra (Azpirotz 740,9 mm).

El resto de observatorios de los valles Cantábricos, registran inferior cantidad de lluvia, pero fueron también muy lluviosos. El valle de Aráitz, Lesaka, Etxalar son más lluviosos que Santesteban-Sunbilla y LekarotzArizkun, por su situación más septentrional y por no actuar la pequeña sombra pluviométrica de los montes del Bidasoa. Santesteban registra resultados superiores a las series históricas $(536,7 \mathrm{~mm}$ en otoño de 1991 y 423,4 mm media histórica), siendo el otoño más lluvioso desde 1976 y uno de los más lluviosos desde 1940 (Gráfico n. ${ }^{\circ}$ 6).

Los valles Pirenaicos se comportan como un segundo foco muy lluvioso en otoño de 1991, pero inferior a los Valles Cantábricos (Gráfico $n .^{\circ} 2$ ). Los observatorios altos de los Pirineos Centrales y el valle del Roncal fueron los lugares más irrigados con más de seiscientos milímetros de precipitación, destacando el valle de Belagua con más de setecientos 
milímetros (Belagua 750,4 mm, Roncesvalles 669,1 mm, Urzainqui 611,8 $\mathrm{mm}$ ). Los valles del Arga y Salazar y la zona de Garralda-Aribe registraron más de quinientos milímetros.

Abaurrea Alta superó la media histórica $(519,4 \mathrm{~mm}$ otoño de 1991 y media histórica $364,8 \mathrm{~mm}$ ) y fue junto con el del 1984 uno de los otoños más lluviosos desde 1940 (Gráfico $n^{\circ}{ }^{7}$ ). Eugi-Esteríbar también fue superior a la media de series históricas (548 mm en otoño de 1991 y 469 $\mathrm{mm}$ media histórica). En esta zona las precipitaciones descendieron de la cabecera a las zonas más bajas de los valles (Irotz $277,8 \mathrm{~mm}$, Navascués $442,3 \mathrm{~mm}$, Epároz $303,8 \mathrm{~mm}$ ). Por lo tanto, la altitud, la proximidad - lejanía al mar en unos casos y la situación latitudinal, marcaron las diferencias, además de factores muy locales como la exposición y orientación con respecto a las montañas.

El sector Cuencas (Gráfico n. ${ }^{\circ} 3$ ) se comporta de manera muy diferente según la situación de los diferentes observatorios. Los valles meridionales húmedos (Anué, Ultzama, Juslapeña, Basaburúa, Larraun) han resultado muy lluviosos en otoño de 1991 y han obtenido una cantidad de precipitación parecida a la de los valles Pirenaicos (Iraitzoz $556,5 \mathrm{~mm}$, Olague $573,7 \mathrm{~mm}$, Irurtzun $437,7 \mathrm{~mm}$ ). El observatorio de Alsasua ha registrado una cantidad de lluvia muy superior a la media de las series históricas (Alsasua $570,3 \mathrm{~mm}$ en otoño de 1991 y $320,7 \mathrm{~mm}$ media de series históricas), siendo el más lluvioso desde 1976 y, junto con este año, el más lluvioso desde 1941 (Gráfico n. ${ }^{\circ}$ 8).

En las áreas montañosas de este sector los resultados se han disparado y han tenido tantas lluvias como en Navarra Húmeda (Goñi 696 $\mathrm{mm}$ y Urbasa $665,3 \mathrm{~mm}$ ). Por el contrario, las cuencas de Pamplona y de Lumbier-Aóiz han sido menos lluviosas, pero próximas a los trescientos milímetros (llundain $341,1 \mathrm{~mm}$, Monreal 273,6 mm). En el observatorio de Pamplona mirando las series históricas (Gráfico $n .^{\circ}$ 9) hemos contado once otoños más lluviosos que este desde 1941 y los años 80 y 84 fueron más lluviosos (Pamplona Observatorio 319,5 mm otoño de 1991 y 220,7 $\mathrm{mm}$ medias series históricas).

En Navarra Media (Gráfico $n .^{\circ} 4$ ) el comportamiento ha sido diferente según las zonas. Han sido muy lluviosos los observatorios próximos a las sierras Exteriores, tanto occidentales como orientales, por el efecto orográfico, superando los cuatrocientos milímetros (Larraona $522,5 \mathrm{~mm}$, Galbarra 455,8 mm, Cáseda 407,6 mm). El observatorio de Yesa (Gráfico $\left.n .^{\circ} 10\right)$ ha superado con mucho las series históricas y se han encontrado siete otoños más lluviosos desde 1940 (337,5 mm otoño de 1991 y 214,2 $\mathrm{mm}$ media de series históricas). 


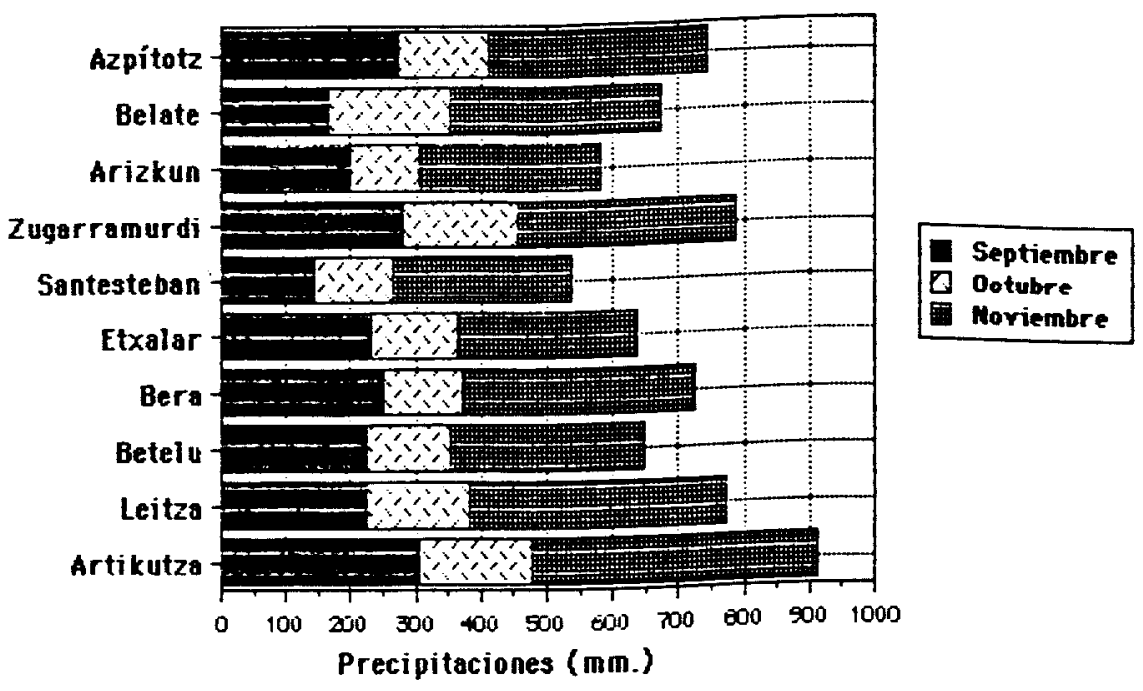

Gráfico 1. NAVARRA HÚMEDA. Precipitaciones de otoño de 1991.

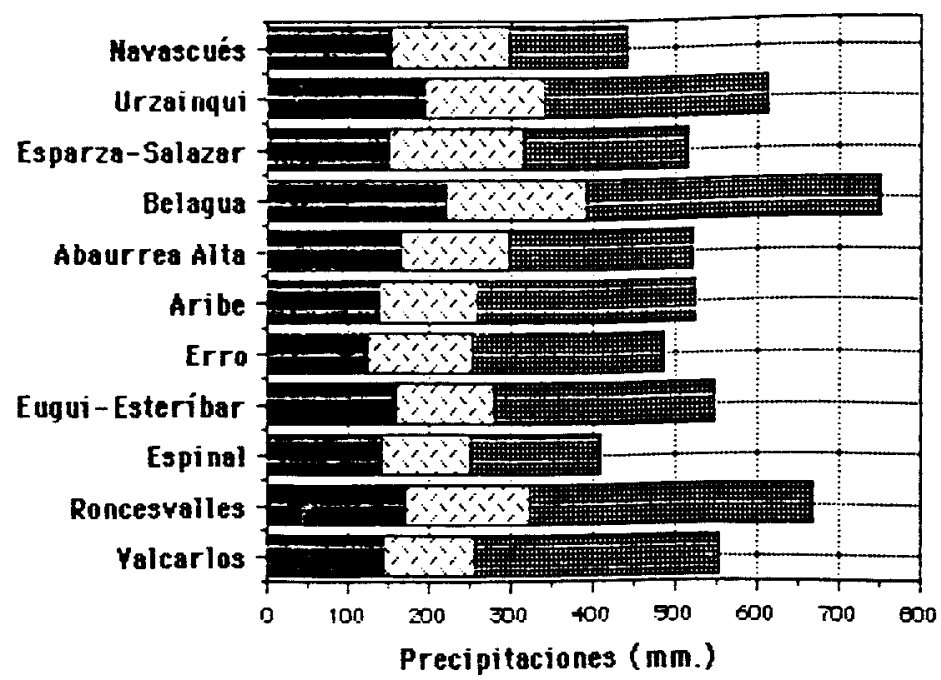

Septiembre

Noviembre

Gráfico 2. NAVARRA PIRENAICA. Precipitaciones de otoño de 1991 


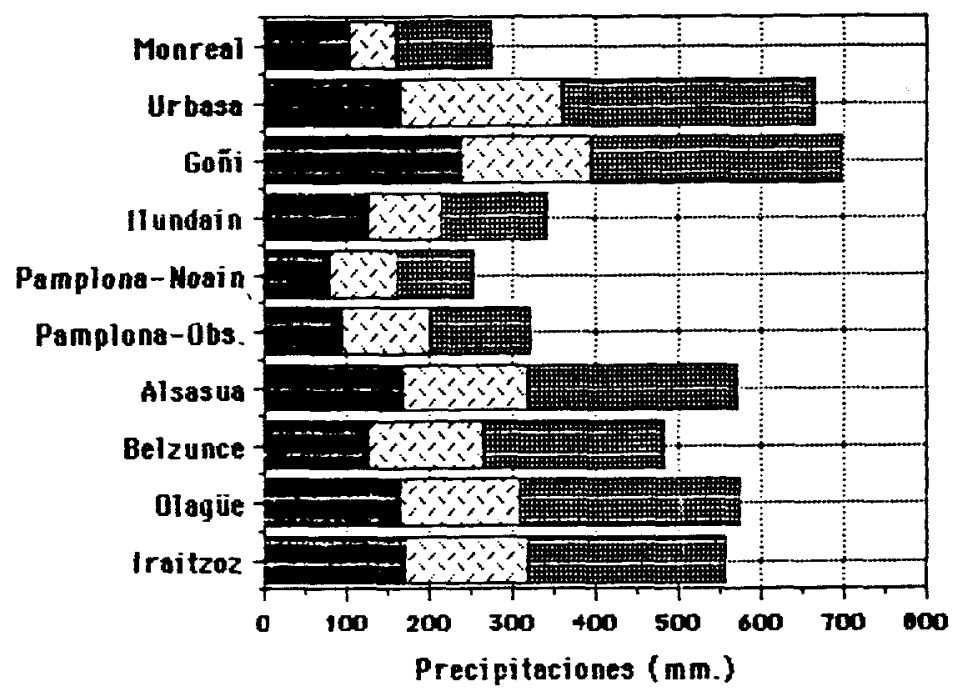

Septiembre

D Octubre

儒 Noriembre

Gráfico 3. LAS CUENCAS. Precipitaciones de otoño de 1991.

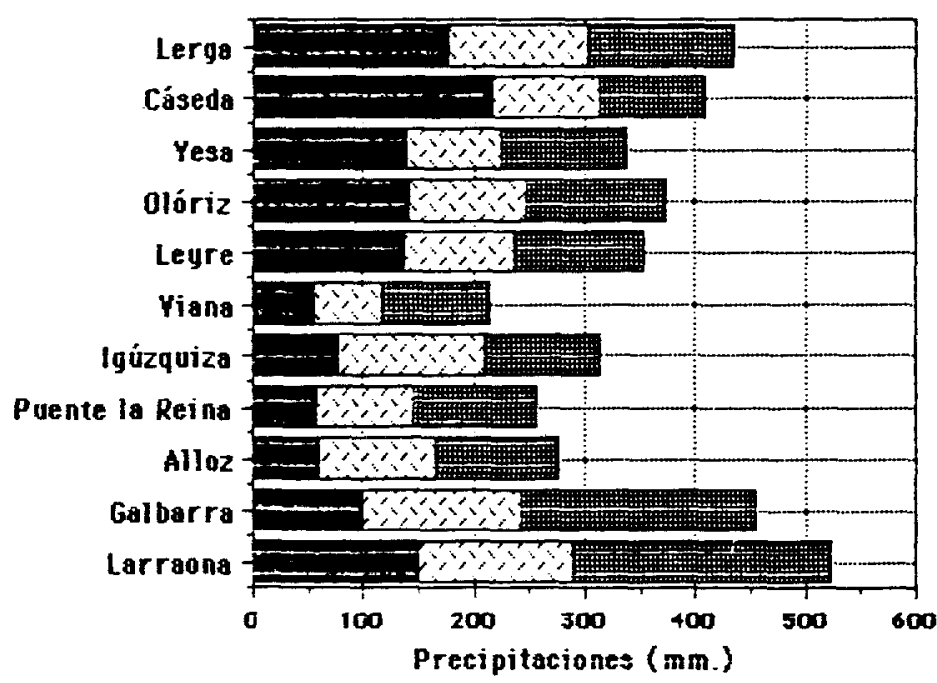

Septiembre Octubre Noriembre

Gráfico 4. NAVARRA MEDIA. Precipitaciones de otoño de 1991 


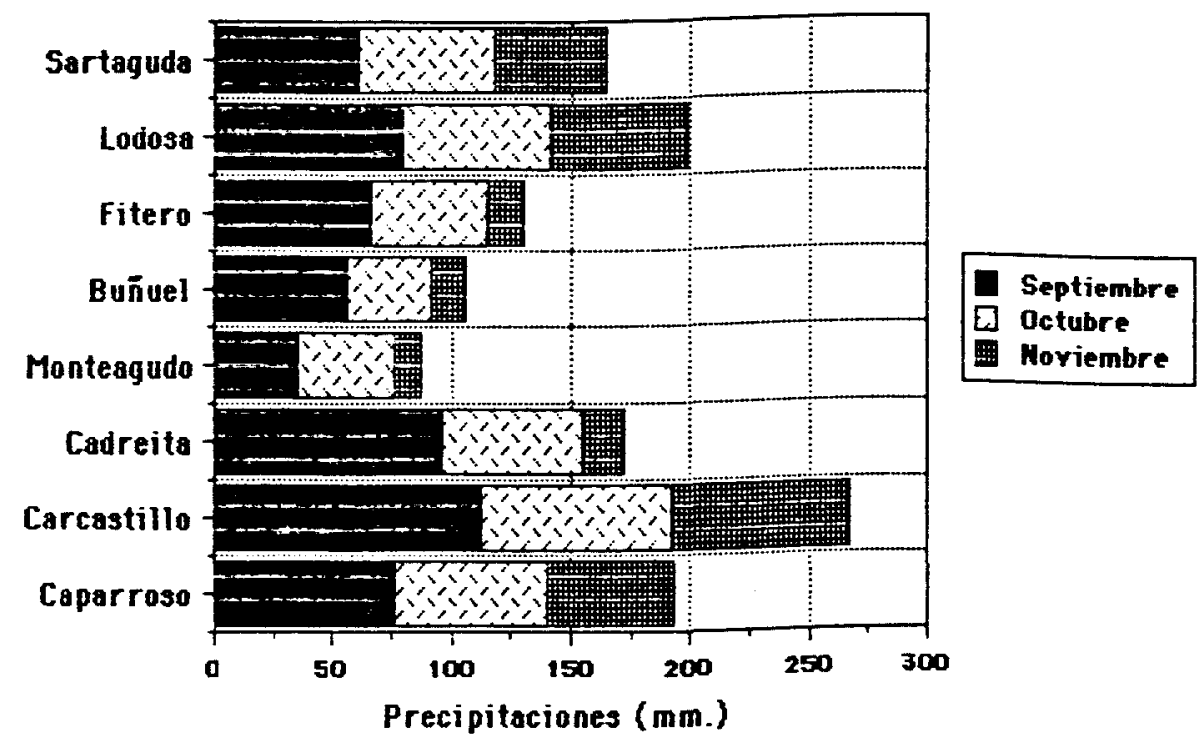

Gráfico 5. LA RIBERA NAVARRA. Precipitaciones de otoño de 1991

El resto ha registrado menos precipitaciones y normalmente con una cantidad recogida inferior a las cuencas de Pamplona y de Lumbier-Aóiz (Alloz $276 \mathrm{~mm}$, Puente la Reina $255,9 \mathrm{~mm}$, Viana 213,5 mm, Olite 252 $\mathrm{mm})$.

La Ribera Navarra ha sido en general más seca que el resto de las comarcas, debido a su mala posición alejada normalmente de las situaciones lluviosas (Gráfico $n .^{\circ}$ ). Sin embargo ha habido diferencias entre unos subsectores y otros. Carcastillo ha sido el más lluvioso con 267,4 $\mathrm{mm}$, resultado muy superior a la media histórica que es de $114,4 \mathrm{~mm}$, por lo que ha sido el otoño más lluvioso desde 1965, año en que se midió una cantidad parecida, y sólo tres otoños, desde 1940, han superado al de 1991 (Gráfico n. ${ }^{\circ}$ 11) El resto de observatorios normalmente supera los ciento cincuenta milímetros, menos el área FiteroMonteagudo, cuyos resultados son más escasos, pero superiores a las medias históricas.

Una vez analizados los datos finales se pueden entresacar las siguientes conclusiones con respecto al otoño muy lluvioso de 1991.

1. Las precipitaciones fueron elevadas en toda la Comunidad, superándose en todos los casos la media histórica. Con respecto a los tres meses del otoño de 1991, se puede afirmar que septiembre fue anormalmente lluvioso, octubre próximo a la media histórica y noviembre, al igual que septiembre, muy lluvioso. La originalidad reside en la interrup- 
$\mathbf{m m}$.

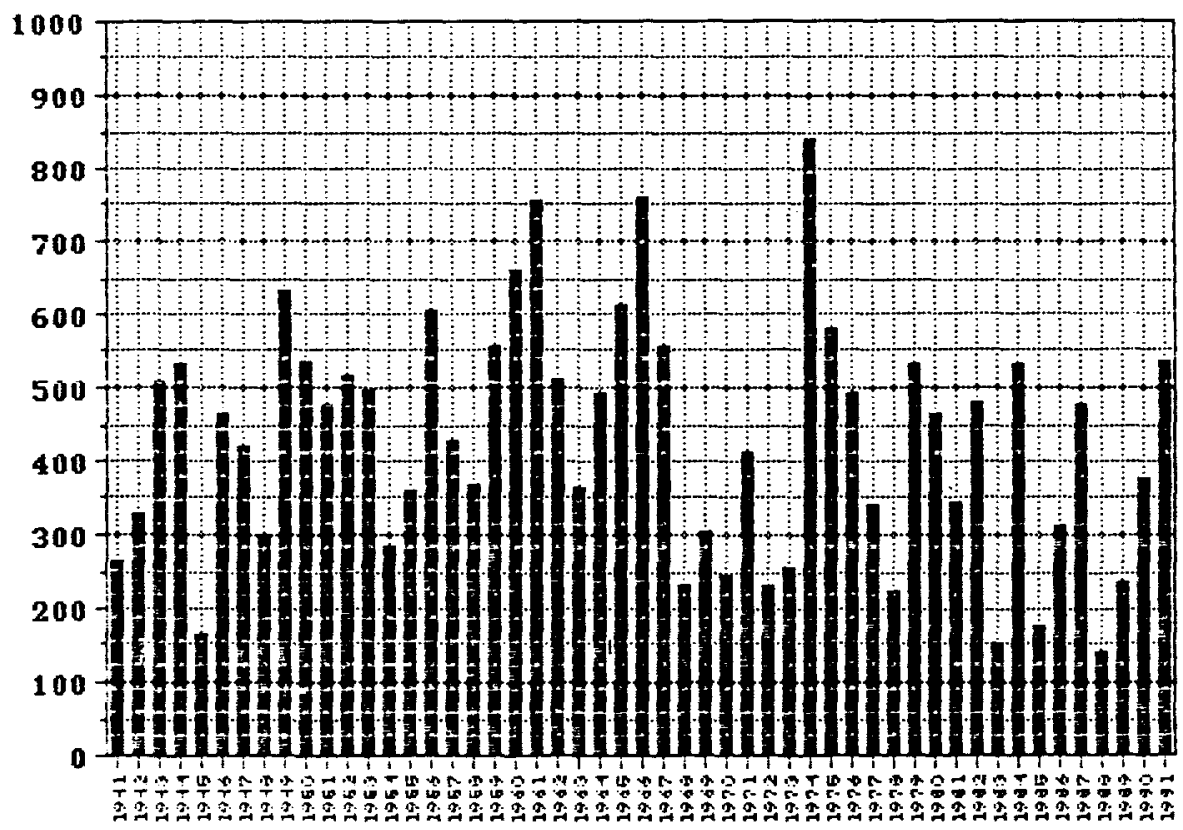

Gráfico 6. SANTESTEBAN. Precipitaciones de otoño en los años 1941-1991

ción de una serie de otoños secos en Navarra, pareciéndose a los otoños de antaño.

2. Los valles Cantábricos, los meridionales húmedos, el corredor de la Barranca, algunos observatorios elevados de Navarra Media Occidental (Larraona-Galbarra), puntos elevados de las sierras Exteriores, la zona Carcastillo-LergaCáseda en Navarra Media Oriental, fueron las zonas más irrigadas de acuerdo con la cantidad recogida en las medias históricas. En estos lugares las precipitaciones fueron muy elevadas y en algunos casos anormalmente altas y escasamente conocidas en las series de larga duración.

En el resto de las comarcas navarras, las lluvias también fueron abundantes y en todos los casos se superaron las medias históricas. Los valles Pirenaicos fueron muy lluviosos, aunque en esta ocasión los valles Cantábricos alcanzaron una mayor cantidad de precipitación. Las cuencas de Pamplona y de Lumbier-Aóiz y la Ribera Navarra, si bien obtuvieron también altas precipitaciones, sus resultados no fueron tan espectaculares, como en las zonas más irrigadas. 
$\mathbf{m} \mathbf{m}$.

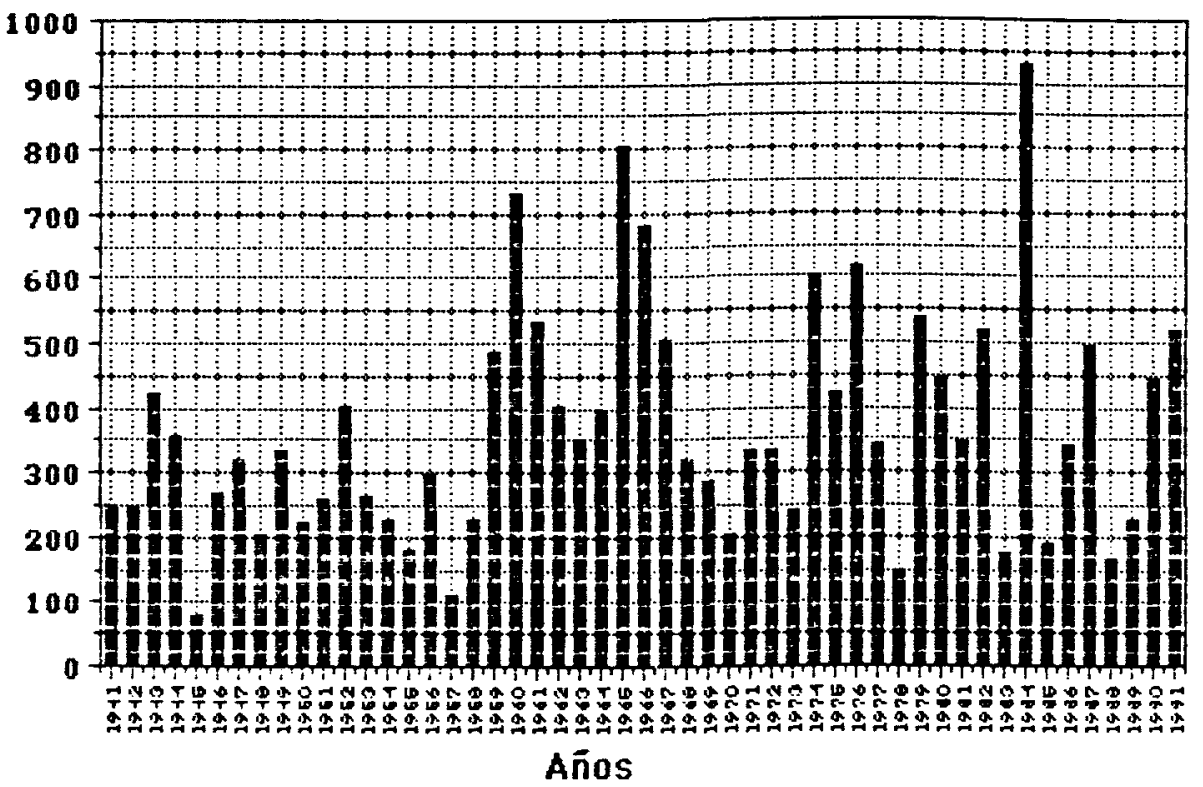

Gráfico 7. ABAURREA ALTA. Precipitaciones de otoño años 1941-1991

3. La dinámica atmosférica de estos tres meses propició la presencia de altas lluvias. En el primer mes, desde el principio, aparecieron situaciones inestables de tormenta con embolsamientos fríos en altura propias del estío, y a finales tuvo lugar la bajada del frente polar, protagonizada por el paso de vaguadas frías, con situaciones del Norte, Oeste y Noroeste. Unas y otras hicieron de este mes un período muy húmedo.

El mes de octubre siguió con la tónica general de situaciones inestables. A mediados, la llegada de una gota fría, que primeramente se instaló al Oeste de Portugal y dio circulación lluviosa del Sudoeste y Oeste, y posteriormente se movió por el Cantábrico, en posición cercana a Navarra, con circulación del Norte, produjo altas precipitaciones.

El mes de noviembre, fue un mes lluvioso típico de otoño, que se caracterizó por la presencia de borrascas profundas, acompañadas de frentes solitarios largos, situadas a la altura de Escocia, con la corriente en chorro del Norte, Noroeste y Oeste, pasando por nuestro territorio, que dio lugar a la llegada de masas de aire polares húmedas e inestables, de largo recorrido por el Atlántico.

Por lo tanto, si el otoño de 1991 fue muy lluvioso se debió en parte a la circulación de la atmósfera, caracterizada por reunir situaciones llu- 
$\mathbf{m} \mathbf{m}$.

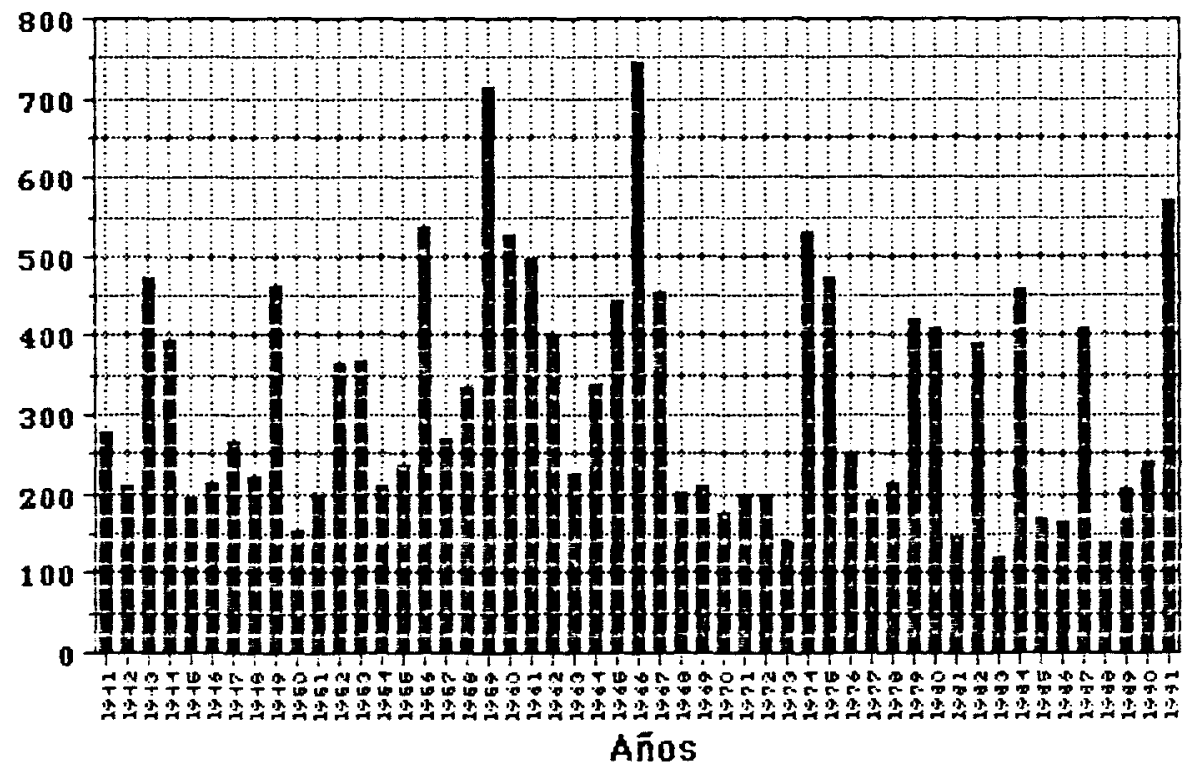

Gráfico 8. ALSASUA. Precipitaciones de otoño, años 1941-1991

viosas propias de verano en septiembre, con la prematura baja del frente polar y paso de los temporales atlánticos; finalmente, con la llegada en noviembre de situaciones lluviosas invernales. La unión de estos tres tipos de circulaciones lluviosas y la escasa presencia de anticiclones persistentes, hizo del otoño de 1991 uno de los más lluviosos de las series históricas.

4. El territorio navarro, por su posición y por su orografía, obtuvo gran cantidad de lluvia. Navarra, junto al Cantábrico Oriental, está bien situada con respecto a las situaciones del Norte, del Noroeste y del Oeste, que predominaron en estos meses. Las masas de aire procedentes del Atlántico Norte, iniciaron su entrada por el Norte de Navarra y como, normalmente eran de mucho gradiente, penetraron, con alguna merma, hacia el interior. Por otra parte las gotas frías se posicionaron en lugares próximos a nuestra geografía.

Más importante, sin embargo, fue la orografía de Navarra. Los macizos de Cinco Villas y Quinto Real y la cadena Divisoria en Navarra Húmeda, los altos Pirineos Orientales en los Valles Pirenaicos y las sierras Exteriores en Navarra Media, hicieron unas veces de pantallas de humedad, tanto en un sentido como en otro; y otras veces ejercieron el papel de activación 
$\mathbf{m} \mathbf{m}$.

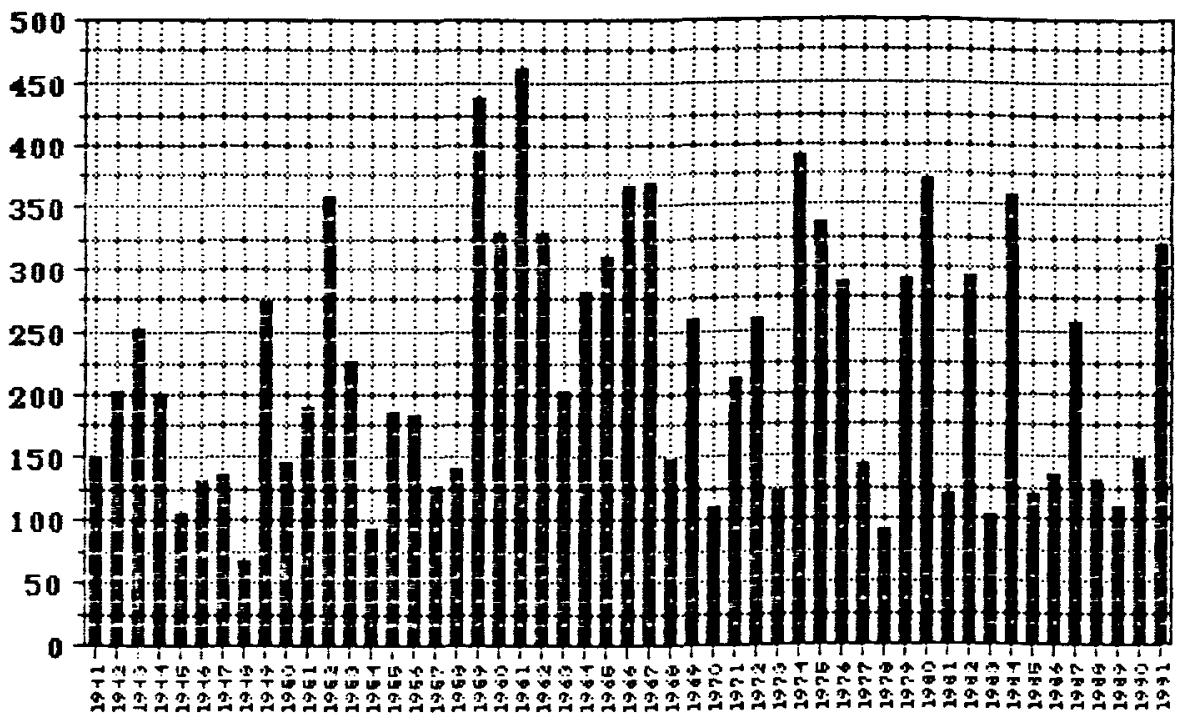

AÑOS

Gráfico 9. PAMPLONA-Obs. Precipitaciones de otoño, años 1941-1991

del mecanismo disparo. Ambas cosas hicieron subir las precipitaciones a cotas elevadas. Los observatorios situados en posiciones cercanas a estas montañas experimentaron un aumento considerable de la cantidad recogida.

5. En general los resultados fueron buenos para la Comunidad $\mathrm{Na}$ varra, que interrumpió los últimos otoños de sequías y aumentó el agua embalsada de los pantanos con relación a su capacidad útil. Fue un agua importante, dado el invierno muy seco que apareció posteriormente.

Sin embargo como efectos negativos hay que anotar los daños causados por las tormentas y el granizo en el Sur de Navarra durante el mes de septiembre, las fuertes crecidas de los ríos y el cierre y uso de cadenas en las carreteras navarras durante el mes de noviembre.

Asi pues, el otoño de 1991 ha pasado a la historia de la climatología navarra como un período altamente lluvioso con una cantidad recogida muy superior a las series históricas en todo el territorio navarro, importante por la interrupción de los últimos otoños secos y originado por dos factores: la circulación de la atmófera y la situación y orografía de Navarra. 
$\mathrm{mm}$.

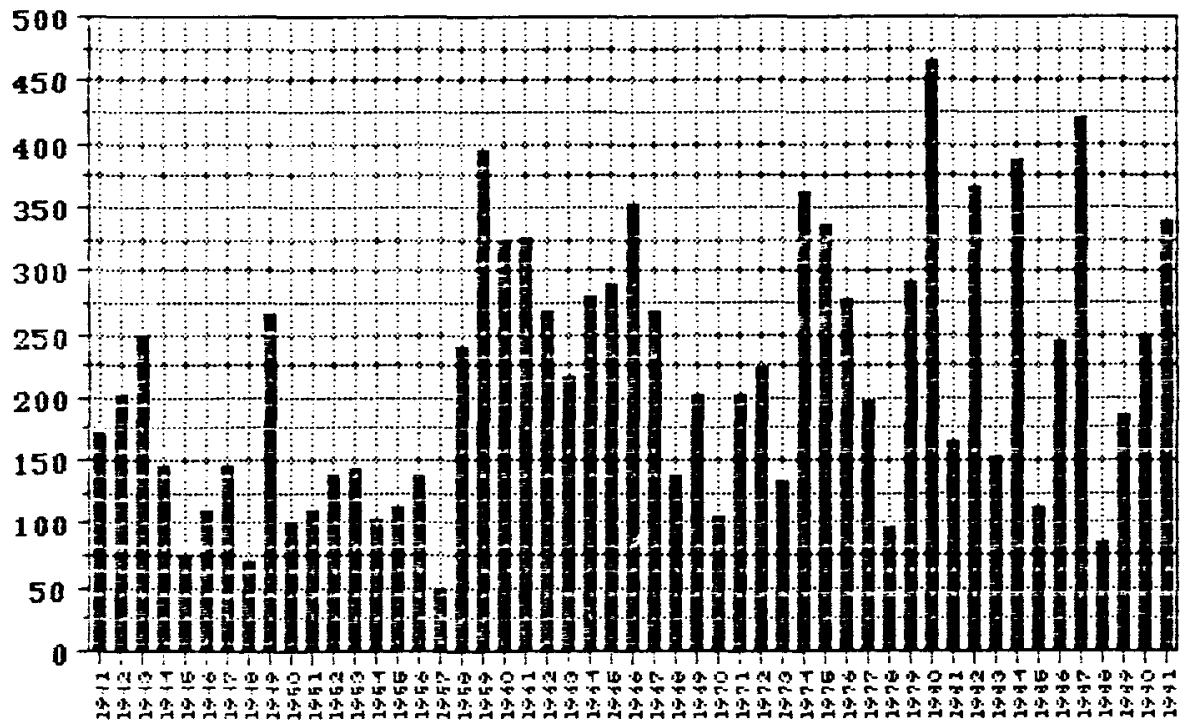

AROS

Gráfico 10. YESA. Precipitaciones de otoño, años 1941-1991

$\mathbf{m m}$.

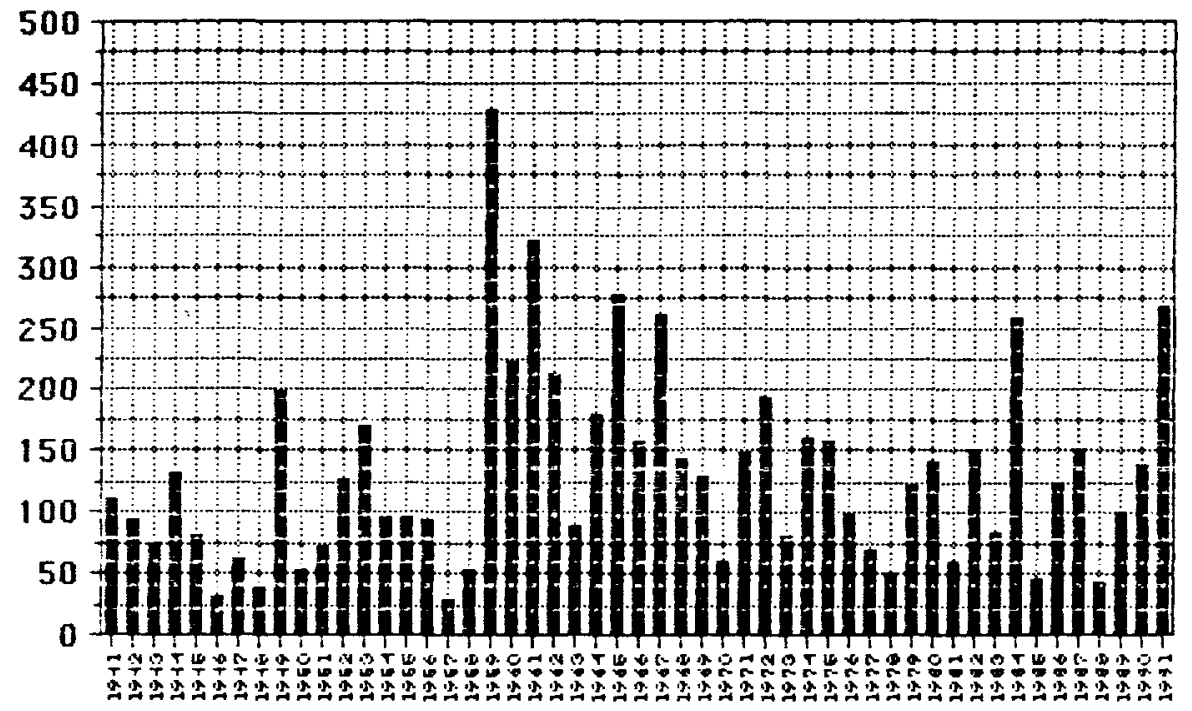

ATHOS

Gráfico 11. CARCASTILLO. Precipitaciones de otoño, años 1941-1991 


\section{BIBLIOGRAFIA}

ALBENTOSA, L. M., 1983: «Precipitaciones excepcionales durante los días 6 a 8 de noviembre de 1982 en Cataluña", Estudios Geográficos, mayo, págs. 229-275, Madrid.

Capel Molina, J., 1981: Los climas de España, Barcelona, Oikos-tau, 429 páginas.

Creus Novau, J., 1986: Climatología (Gran Atlas Geográfico e Histórico de Navarra), Pamplona, Caja de Ahorros de Navarra, págs. 83-90.

- 1990: Climatología (Gran Enciclopedia Navarra). Pamplona, Caja de Ahorros de Navarra.

Creus, J. y Puigdefabregas, J. 1978: “Influencia del relieve en la distribución de las precipitaciones máximas. Un ejemplo Pirenaico", Cuadernos de Investigación, 4, págs. 11. 23, Colegio Universitario de Logroño.

Creus, J., Puigdefabregas, J. y Garcia, J. M. 1981: “Precipitaciones máximas en varios días consecutivos en la provincia de Huesca y probabilidades de ocurrencia de varios períodos secos de distinta duración", Comunicación presentada al VII Coloquio de Geografía. Pamplona, 1981.

DORIZE, L. 1983: "Quelques remarques concernant les amomalies pluviometriques", Bull. Assoc. Geog. Frac., 494, págs. 119-130, Paris.

Elías CAstillo, F. y Ruiz Beltrán, L., 1982: Estudio agroclimático de la provinica de Navarra. Pamplona, Instituto Navarro del Suelo, 332 páginas

- 1986: Caracterización agroclimática de Navarra. Pamplon a, Ministerio de Agricultura, Pesca y Alimentación y Departamento de Agricultura, Ganadería y Montes del Gobierno de Navarra, 226 páginas.

García, J. Puigdefábregas J. y Martín-Ranz, M.C., 1983: “Diferencias espaciales en la respuesta hidrológica a las precipitaciones torrenciales de Noviembre de 1982 en el Pirineo Central», Estudios Geográficos, 171, págs. 291-311, Madrid.

García Fernández, J., 1986: El clima en Catilla y León. Valladolid. Ámbito, 370 páginas.

GIL OLCINA, A., 1983: "Inundaciones de octubre de 1982 en el campo de Alicante», Estudios Geográficos, 171, págs. 121-143, Madrid.

LINÉs, A., 1981: «Perturbaciones tipicas que afectan a la Península lbérica y precipitaciones asociadas. Madrid INM, serie A-80, 64 páginas.

LISO, A. y AsCASO, A., 1969: "Introducción al estudio de la evapotranspiración y clasificación climática de la Cuenca del Ebro", Anales Est. Expág. Aula De $i$ (CSIC). Zaragoza.

MARTíN VIDE, J., 1979: Característiques climatologiques de la precipitació en la franja costera Mediterranea de la Península Ibérica. Barcelona, Generalitat de Catalunya, 246 páginas.

- 1979: «Frecuencias diarias de la precipitación en Barcelona. Singularidades", Notes de Geografía Física 1, págs. 25-33. Universidad de Barcelona. Departamento de Geografía, Universidad de Barcelona.

- 1980: «Persistencia de los días con y sin precipitación en Barcelona (Observatorio de Fabra)", Revista de Geografía, XIV, 1 y 2, págs. 39-57. Universidad de Barcelona. Departamento de Geografía.

MARZOL JAÉN, V. 1988: La lluvia, un recurso natural para Canarias. Tenerife, Caja General de Ahorros de Canarias, 220 páginas.

MENSUA, S. 1968: "La zonificación bioclimática de Navarra", en homenaje al prof. D. José María Lacarra de Miguel. Zaragoza, págs. 362-376.

Pejenaute GoñI, J. 1990: Tipos de tiempo y clima de las comarcas navarras. Pamplona, Príncipe de Viana, 545 páginas.

- 1989: "Los días de precipitación elevada en Navarra y las situaciones atmosféricas que los originan", Notas y Estudios de Ciencias Sociales, 2, págs. 17-60. Pamplona. Centro Asociado de la UNED de Navarra, Pamplona.

- 1989: "Atmósfera y territorio. Factores que condicionan el clima de Navarra" (Lección apertura de curso 1989-90), Centro Asociado de la UNED en Pamplona, serie lecciones, 25 páginas.

- 1990: "Estudio del periodo seco otoño-invierno 1988-89 en Navarra". Notas y Estudios de Ciencias Sociales, 3, págs. 97-130. Pamplona. Centro Asociado de la UNED en Navarra.

- 1990: “Las situaciones atmosféricas Iluviosas en Navarra", Espacio, Tiempo y Forma, serie VI, Geografía, págs. 113-150. Madrid. Universidad a Distancia. 
- 1990: «Introducción al estudio de la climatología en Navarra», Lurralde, 13, págs. 43-62. San Sebastián. INGEBA.

- 1991: "El comportamiento climático original de los meses de noviembre y diciembre de 1989 en Navarra", Estudios de Ciencias Sociales, 4, págs. 199-223. Pamplona. Centro Asociado de la UNED de Navarra.

- 1990: "Estudio de las precipitaciones torrenciales de agosto de 1983 en Navarra", Lurra/de, 14, págs. 117-142. San Sebastián. INGEBA.

- 1992: El clima de Navarra. Pamplona, Ediciones Eunate, 223 páginas.

- 1993: El clima de Pamplona. Pamplona, Ayuntamiento de Pamplona, 104 páginas.

QUEREDA, J. 1984: "Perturbations atmospheriques et temperature merine en Méditerranée Occidentale", Mediterranée, 3, págs.11-16, Aix.

- 1984: “Los excepcionales temporales de octubre y su relación con las temperaturas del mar", Cuadernos Geográficos de Valencia. Valencia, págs. 1-13.

- 1989: la ciclogénesis y las gotas frías en el Mediterráneo Occidental. Castellón, Colegio Universitario y Diputación, 136 pág.

Ruiz Urrestarazu. E., 1982: La transición climática del Cantábrico Oriental al Valle Medio del Ebro. Vitoria, Diputación Provincial de Alava, 651 páginas.

SANCHO, J. 1977: "Frecuencia e intensidad de las precipitaciones en Bilbao, San Sebastián, Vitoria, Pamplona y Logroño», Cuadernos de Investigación, 3, págs. 3-14, Colegio Universitario de Logroño.

Uriarte, A. 1983: El régimen de precipitaciones en la costa NW. y N. de la Península lbérica. San Sebastián, Caja de Ahorros de Guipúzcoa, 550 páginas.

- 1981: “Estudio comparativo de la marcha de precipitaciones por períodos de cinco días en Vigo y en San Sebastián", Lurralde, págs. 115-120, San Sebastián, INGEBA.

- 1982: "Duración de las precipitaciones e intensidades en tiempos cortos en San Sebastián", Lurralde, págs. 21-34, San Sebastián, INGEBA. 